\title{
HIF-1 $\alpha$ induces glycolytic reprogramming in tissue-resident alveolar macrophages to promote survival during acute lung injury
}

\author{
${ }^{1}$ Parker S. Woods, ${ }^{1}$ Lucas M. Kimmig, ${ }^{1}$ Kaitlyn A. Sun, ${ }^{1}$ Angelo Y. Meliton, \\ ${ }^{1}$ Obada R. Shamaa, ${ }^{1}$ Yufeng Tian, ${ }^{1}$ Rengül Cetin-Atalay, ${ }^{2}$ Willard W. Sharp, \\ ${ }^{1}$ Robert B. Hamanaka, and ${ }^{1}$ Gökhan M. Mutlu
}

Department of Medicine, ${ }^{1}$ Section of Pulmonary and Critical Care Medicine, and ${ }^{2}$ Section of Emergency Medicine, The University of Chicago, Chicago, IL 60637

Corresponding Author:

Gökhan M. Mutlu, MD

The University of Chicago

Section of Pulmonary and Critical Care Medicine

5841 S. Maryland Avenue

MC6026

Chicago, IL 60637

Phone: 773-702-1002

Fax: $773-702-6500$

Email: gmutlu@medicine.bsd.uchicago.edu 


\section{$1 \quad$ ABSTRACT}

2 Cellular metabolism is a critical regulator of macrophage effector function. Tissue-resident

3 alveolar macrophages (TR-AMs) inhabit a unique niche marked by high oxygen and low glucose.

4 We have recently shown that in contrast to bone marrow-derived macrophages (BMDMs), TR-

5 AMs cannot utilize glycolysis and predominantly rely on mitochondrial function for their effector

6 response. It is not known how changes in local oxygen concentration that occur during conditions

7 such as acute respiratory distress syndrome (ARDS) might affect TR-AM metabolism and

8 function; however, ARDS is associated with progressive loss of TR-AMs, which correlates with

9 the severity of disease and mortality. Here, we demonstrate that hypoxia robustly stabilizes HIF-

$101 \alpha$ in TR-AMs to promote a glycolytic phenotype. Hypoxia altered TR-AM metabolite signatures,

11 cytokine production, and decreased their sensitivity to the inhibition of mitochondrial function. By

12 contrast, hypoxia had minimal effects on BMDM metabolism. The effects of hypoxia on TR-AMs

13 were mimicked by FG-4592, a HIF-1a stabilizer. Treatment with FG-4592 decreased TR-AM

14 death and attenuated acute lung injury in mice. These findings reveal the importance of

15 microenvironment in determining macrophage metabolic phenotype, and highlight the therapeutic

16 potential in targeting cellular metabolism to improve outcomes in diseases characterized by acute

17 inflammation. 


\section{INTRODUCTION}

19 Glycolytic metabolism has been ascribed a central role in macrophage inflammatory processes

20 (Tannahill, Curtis et al. 2013, Freemerman, Johnson et al. 2014, Palsson-McDermott, Curtis et

21 al. 2015, Xie, Yu et al. 2016, Ip, Hoshi et al. 2017). Much of our current understanding of this

22 phenomena has been elucidated in bone marrow-derived macrophages (BMDMs) and

23 macrophage cell lines (i.e., THP-1 and RAW 264.7), which model macrophages of monocytic

24 lineage. Considerably less is known about how other factors like local microenvironment and

25 developmental origin may influence macrophage metabolic function. Tissue-resident alveolar

26 macrophages (TR-AMs) reside within the lumen of the lung alveolus where they are critical in

27 maintaining lung homeostasis within the healthy airway and are the first responders to airborne

28 pathogens and pollutants (Hussell and Bell 2014). The alveolus maintains the highest oxygen

29 concentration of any tissue compartment within the human body (Carreau, El Hafny-Rahbi et al.

30 2011). Moreover, under steady-state conditions, glucose concentrations within airway lumen are

31 less than one-tenth of blood glucose concentrations (Baker, Clark et al. 2007). These

32 environmental conditions alone suggest a requirement for oxidative metabolism for cells that

33 reside within the alveoli. Several studies have demonstrated that the unique characteristics of the

34 alveolar microenvironment heavily influence macrophage function and immunometabolism

35 (Lavin, Winter et al. 2014, Svedberg, Brown et al. 2019, McQuattie-Pimentel, Ren et al. 2021).

36 Our group has recently demonstrated that TR-AMs rely predominantly on oxidative

37 phosphorylation under steady-state conditions and that glycolysis is dispensable for

38 proinflammatory effector function in these cells (Woods, Kimmig et al. 2020). Together, these

39 findings highlight the lung microenvironment's central role in dictating TR-AM responses.

41 Conditions associated with severe airway inflammation (i.e., acute respiratory distress syndrome

42 (ARDS)) increase alveolar epithelial/endothelial barrier permeability (Ware and Matthay 2000).

43 This results in flooding of alveoli with fluid and recruitment of non-resident immune cells leading 
44 to severe local hypoxia as well as an increase in alveolar glucose levels (Fröhlich, Boylan et al.

45 2013, Campbell, Bruyninckx et al. 2014, Baker and Baines 2018). These abrupt changes in the

46 alveolar microenvironment under a diseased state such as ARDS likely necessitate metabolic

47 adaptation by TR-AMs in order to ensure optimal cellular fitness. Acute lung injury/ARDS is

48 associated with a decline in the number of TR-AMs and the degree of TR-AM loss correlates with

49 clinical outcomes (i.e., mortality) (Fan and Fan 2018). Moreover, experimental depletion of TR-

50 AMs results in an increase in the severity of acute lung injury and mortality (Beck-Schimmer,

51 Schwendener et al. 2005, Kim, Lee et al. 2008, Jaworska, Coulombe et al. 2014, Machado-

52 Aranda, V Suresh et al. 2014, Nelson, Zhou et al. 2014, Schneider, Nobs et al. 2014, Cardani,

53 Boulton et al. 2017). Whether or not changes in the alveolar microenvironment play a role in TR-

54 AM cell death during acute lung injury/ARDS has yet to be explored.

Hypoxia-inducible factor 1 -alpha (HIF-1 $\alpha)$ is the most extensively characterized transcription

57 factor responsible for cellular adaptation to low oxygen levels (Semenza 2012). In brief, under normoxia, oxygen-dependent proline hydroxylases prevent HIF-1 $\alpha$ activation by marking it for proteasomal degradation. Conversely, under hypoxia, decreased hydroxylase activity promotes HIF-1 $\alpha$ protein stabilization and translocation to the nucleus allowing for transcriptional responses

61 to low oxygen levels, such as enhanced expression of genes related to glycolysis and

62 angiogenesis. HIF-1 $\alpha$ has been well characterized in macrophages of monocytic origin, and

63 identified to play a key role in macrophage infiltration and proinflammatory responses (Cramer,

64 Yamanishi et al. 2003, Peyssonnaux, Datta et al. 2005, Tannahill, Curtis et al. 2013, Matak, Heinis

65 et al. 2015, Palsson-McDermott, Curtis et al. 2015). However, little is known about the role that

66 HIF-1a plays in TR-AM effector function and metabolism. In a study focusing on TR-AM

67 development, Izquierdo et al demonstrated that the expression of HIF-1 $\alpha$ and its target genes is

68 turned off following birth and this process is required for TR-AM maturation and normal effector

69 function (Izquierdo, Brandi et al. 2018). It is unknown; however, whether HIF-1a plays a role in 
70 TR-AM effector function after maturation or how local hypoxia and changes in the expression of

71 HIF-1 $\alpha$ might regulate the adaptation of mature TR-AMs to hypoxia or affect their effector function

72 during acute lung injury.

73

74 To answer these questions, we used a variety of metabolic and immunological approaches. We

75 observed that HIF-1 $\alpha$ was undetectable in primary TR-AMs cultured under normoxia, but was

76 robustly stabilized under hypoxia in a dose-dependent fashion. Upon hypoxic HIF-1a stabilization,

77 TR-AMs acquired a glycolytic phenotype, which was not observed under normoxic conditions. In

78 contrast, BMDMs exhibited no alterations in HIF-1 $\alpha$ stabilization or glycolytic output in response

79 to hypoxia. Analysis of LPS-induced TR-AM metabolite signatures revealed significant increases

80 in glycolytic intermediates under hypoxia. Hypoxia also altered TR-AM cytokine profile in

81 response to LPS. In contrast to BMDMs, TR-AMs depend on mitochondrial function for

82 inflammatory responses under normoxia. Hypoxia rescued the ETC inhibitor-induced impairment

83 in cytokine production in TR-AMs.

85 Using influenza infection in mice to model acute lung injury, we found that TR-AM cell number 86 decreased over the course of acute lung injury. Surviving TR-AMs exhibited a glycolytic gene 87 signature supporting hypoxic adaptation. To determine how the ability to adapt to hypoxia affects

88 TR-AM survival and function, we treated influenza-infected mice intratracheally with FG-4592, a

89 HIF-1a stabilizer, which mimics hypoxic adaptation. Compared to control mice, FG-4592

90 prevented the loss of TR-AMs, reduced lung injury, and increased survival. Collectively, our data

91 suggest that HIF-1a plays a critical role in TR-AM metabolic adaptation to altered environmental

92 conditions during acute lung injury. Promoting hypoxic adaptation and glycolytic metabolism in

93 TR-AMs enables them to adapt to and survive the changes in the microenvironment during lung

94 injury and consequently reduces lung inflammation and may offer a viable therapeutic strategy in

95 treating ARDS arising from influenza or other severe viral infections, including COVID19. 


\section{RESULTS}

97 Tissue-resident alveolar macrophages exhibit HIF-1 a stabilization and develop a glycolytic

98 phenotype in response to hypoxia

99 We have recently shown that TR-AMs maintain a very low glycolytic rate which is not augmented

100 by activation of inflammatory responses (Woods, Kimmig et al. 2020). As TR-AMs inhabit an

101 environment with high oxygen levels, we hypothesized that TR-AMs may not be able to induce

102 glycolytic reprogramming in response to either inflammatory stimuli or to physiologic hypoxia.

103 Glycolysis stress tests were performed following overnight (16 hours) exposure to decreasing

104 levels of ambient oxygen. Unlike the inability of TR-AMs to induce glycolysis after inflammatory

105 stimulus under normoxia, they exhibited a progressive increase in the extracellular acidification

106 rate $(E C A R)$ in response to escalating degrees of ambient hypoxia (Figure $1 \mathrm{~A})$. Both basal rate

107 of glycolysis and glycolytic reserve increased substantially when oxygen levels were lowered to

$108 \quad 3.0 \%$ and $1.5 \%$ (Figure 1B). HIF-1 1 levels were nearly undetectable under normoxic conditions;

109 however, with increasing degrees of hypoxia, HIF-1a stabilization occurred in a dose-dependent

110 fashion and was detectable in the nucleus (Figure 1C). Intracellular lactate levels increased

111 slightly in TR-AMs after exposure to hypoxia compared with normoxic control cells while the

112 lactate levels in the media increased by a greater degree (Figure 1D). Pretreating TR-AMs prior

113 to hypoxia with echinomycin, an inhibitor of HIF-1a DNA binding activity (Kong, Park et al. 2005),

114 disrupted hypoxia-induced increases in glycolytic output in a dose-dependent fashion (Figure 1E).

115 Echinomycin also reduced hypoxia-induced increases in glycolytic protein expression (LDHA and

116 HK2), suggesting that HIF-1 $\alpha$ is required for glycolytic adaption to hypoxia in TR-AMs (Figure 1F).

118 Both short-term (2 hours) and prolonged (16 hours) exposure to hypoxia $\left(\begin{array}{lll}1.5 \% & \mathrm{O}_{2}\end{array}\right)$ led to 119 significant increases in nuclear HIF-1a protein levels in TR-AMs (Figure S1A). Glycolysis stress

120 tests demonstrated that short-term hypoxia treatment failed to induce significant alterations in 121 glycolysis or glycolytic capacity in TR-AMs compared to prolonged hypoxia treatment suggesting 
122 that transcription and translation of glycolytic genes that are targets of HIF-1a are required (Figure

123 S1B,C). Taken together, these data indicate that TR-AM HIF-1a stabilization in response to

124 hypoxia is dose-dependent, and that prolonged hypoxia, but not short-term hypoxia exposure,

125 leads to a functional glycolytic phenotype in TR-AMs.

127 BMDMs have limited metabolic adaptation to hypoxia

128 Several studies have examined the effects of hypoxia on BMDM metabolism; however, they

129 focused heavily on transcriptional changes in glycolytic gene expression as opposed to functional 130 changes in glycolysis (Bosco, Puppo et al. 2006, Roiniotis, Dinh et al. 2009, Delprat, Tellier et al.

131 2020). We found that, unlike TR-AMs, BMDMs exposed to hypoxia (16 hours) exhibit minimal 132 changes in glycolytic rate or glycolytic capacity (Figure 2A-B). Interestingly, we found that BMDMs 133 have high basal levels of nuclear HIF-1a protein under normoxic conditions and that HIF-1a 134 expression in BMDMs did not significantly change in response to hypoxia as low as $1.5 \% \mathrm{O}_{2}$ 135 (Figure 2C). Exposure to hypoxia resulted in only a small increase in extracellular lactate levels 136 (Figure 2D), which is in agreement with the glycolysis stress test data. Echinomycin had a minimal 137 effect on the glycolytic output of hypoxic BMDMs (Figure 2E). Likewise, neither hypoxia nor 138 hypoxia in combination with echinomycin altered glycolytic protein expression (LDHA and HK2) 139 in BMDMs (Figure 2F). Duration of hypoxia exposure (2h vs $16 \mathrm{~h}$ ) had no significant effect on HIF140 1a stabilization or glycolysis in BMDMs (Figure S2A-C). Collectively, these data demonstrate that 141 hypoxia has minimal effect on glycolytic function and HIF-1a stabilization in BMDMs. 
144 The hypoxia-induced transcriptomic response differs substantially between TR-AMs and

\section{BMDMs}

146 To better understand the observed differences in hypoxia-induced glycolytic metabolism between

147 TR-AMs and BMDMs, we performed RNA-sequencing to assess global alterations in gene 148 expression. We found 741 DEGs (512 upregulated and 229 downregulated) in TR-AMs in 149 response to $1.5 \% \mathrm{O}_{2}$ compared to only 260 DEGs (214 upregulated and 46 downregulated) in 150 BMDMs (Figure 3A). Reactome pathway analysis revealed that hypoxia altered a large number 151 of TR-AM genes in multiple pathways ranging from cellular metabolism, hemostasis, and immune 152 cell function, while the majority of BMDM genes affected by hypoxia were related to carbohydrate 153 metabolism (Figure 3B). Hypoxia led to the most significant increases in glycolytic and HIF-1a 154 regulatory gene expression in both TR-AMs and BMDMs. These same genes were significantly 155 lower in TR-AMs compared to BMDMs under normoxic conditions (Figure 3C). This is in direct agreement with our previous findings (Woods, Kimmig et al. 2020). A side-by-side comparison

157 demonstrated that the level of HIF-1 $\alpha$ expression in hypoxic TR-AMs is similar to that of BMDMs under normoxia and hypoxia (Figure 3D). Hypoxia-induced HIF-1a expression in TR-AMs correlated with increase in glycolytic (HK2 and LDHA) and prolyl hydroxylase (EGLN1 and EGLN3) protein expression in TR-AMs (Figure 3E). This was not the case in BMDMs in which

161 hypoxia exposure did not alter protein expression of glycolytic genes. These results demonstrate 162 that hypoxia induces transcriptomic alterations in TR-AMs that lead to changes in protein 163 expression and metabolic function. In contrast, BMDMs exhibit high levels of HIF-1 $1 \alpha$ and HIF-1 $\alpha$ 164 target proteins at baseline, and do not further increase the expression of these proteins in 165 response to hypoxia, despite a hypoxia-adaptive mRNA transcription (Figure 3D and 3E).

167 Hypoxia modulates TR-AM cytokine production and metabolic response to LPS

168 Hypoxia and HIF-1 $1 \alpha$ are thought to be central to the inflammatory response of macrophages 169 (Cramer, Yamanishi et al. 2003, Tannahill, Curtis et al. 2013, Palsson-McDermott, Curtis et al. 
170 2015). To determine the effect of HIF-1a stabilization on TR-AM's effector response, we

171 measured the production of proinflammatory cytokines in response to LPS under hypoxia. TR-

172 AMs were exposed overnight to hypoxia $\left(1.5 \% \mathrm{O}_{2}\right)$ or normoxia and then subsequently treated

173 with LPS while maintaining original $\mathrm{O}_{2}$ conditions. Hypoxia alone did not stimulate cytokine

174 production without LPS treatment. Hypoxic TR-AMs secreted significantly higher levels of TNF-a,

$175 \mathrm{KC}$, and IL-1 $\beta$ in response to LPS compared to normoxic controls. In contrast, IL-6 and CCL2

176 secretion was decreased in hypoxic TR-AMs (Figure 4A). The cytokine gene expression pattern

177 in hypoxic TR-AMs treated with LPS mirrored the secreted cytokine profile (Figure 4B). Moreover,

178 enhanced prolL-1 $\beta$ protein production was observed in hypoxic TR-AMs treated with LPS (Figure

179 4C). While BMDMs experienced limited metabolic alterations in response to hypoxia, treatment

180 with LPS revealed that hypoxia induced similar alterations in their cytokine profile. Hypoxic

181 BMDMs had increased TNF- $\alpha, \mathrm{KC}$, and IL-1 $\beta$, and decreased IL-6 secretion (Figure S3A). The

182 only discordance in the hypoxic cytokine response profile between TR-AMs and BMDMs was

183 CCL2, which remained unchanged in hypoxic BMDMs in response to LPS compared to normoxic

184 controls (Figure S3A).

186 We and others have shown that BMDMs exhibit an immediate enhancement in glycolytic output

187 in response to LPS (Figure S4). It is thought that this increase in glycolysis following LPS supports

188 the proinflammatory response. We have shown that LPS-induced inflammation in TR-AMs is

189 independent of glycolysis including the rise in glycolysis following LPS injection (Woods, Kimmig

190 et al. 2020). Given that hypoxia elevated HIF-1 a levels and glycolytic rates in TR-AMs, we sought

191 to determine if hypoxia could alter TR-AM glycolytic responsiveness to LPS. We found that

192 despite the fact that hypoxia increased the glycolytic rate of TR-AMs at baseline, TR-AM

193 glycolysis remained unresponsive to LPS injection (Figure 4D). Using capillary electrophoresis-

194 mass spectrometry to measure glycolytic metabolite levels, we found that consistent with

195 increased glycolytic output after hypoxia, levels of glycolytic intermediate metabolites (glucose-6 
196 phosphate, fructose 1,6 diphosphate, glycerol 3-phosphate, dihydroxyacetone phosphate) and

197 lactate were increased in response to hypoxia alone. Interestingly, hypoxic TR-AMs exhibited

198 further increases in glycolytic intermediates in the presence of LPS (6h) compared to normoxic

199 cells, suggesting that while LPS increases cellular levels of glycolytic metabolites in hypoxic TR-

200 AMs, this does not manifest as acute lactate secretion (Figure 4E). These data demonstrate that

201 hypoxia leads to significant alterations in TR-AM cytokine production and increased glycolytic

202 metabolites in response to prolonged LPS treatment. However, unlike the prototypical BMDM

203 response, hypoxic TR-AMs do not immediately increase their extracellular acidification in

204 response to LPS.

205

206 We have previously shown that unlike BMDMs, TR-AMs effector function is acutely sensitive to

207 mitochondrial inhibition (Woods, Kimmig et al. 2020). Since TR-AM capacity for glycolysis

208 expands with decreasing levels of $\mathrm{O}_{2}$, we next sought to assess mitochondrial function under

209 hypoxia and performed a mitochondrial stress test on TR-AMs that had been exposed to varying

210 oxygen concentrations. Interestingly, mild-to-moderate degrees of ambient hypoxia did not

211 appear to significantly alter overall mitochondrial function in these cells. Only $1.5 \% \mathrm{O}_{2}$ caused

212 significant reductions in oxygen consumption rate (OCR) across all mitochondrial parameters

213 (Figure 5A, B). ECAR tracings during the mitochondrial stress test demonstrated that, other than

214 severe hypoxia $\left(1.5 \% \mathrm{O}_{2}\right)$, the majority of acid produced under mild-moderate hypoxia is derived

215 from $\mathrm{CO}_{2}$, as the application of rotenone and antimycin A led to a significant reduction in ECAR

216 (Figure $5 \mathrm{C}$ ). When exposed to $1.5 \% \mathrm{O}_{2}$, TR-AM energy is derived mostly from glycolysis with little

217 TCA activity and no significant contribution of $\mathrm{CO}_{2}$ to extracellular acidification. Overall BMDM

218 mitochondrial function was impaired by $1.5 \% \mathrm{O}_{2}$, but the effect was greatly diminished compared

219 to TR-AMs (Figure S5A, B). BMDM ECAR tracing during mitochondrial stress test demonstrated

220 that most acid production remained unchanged in response to rotenone and antimycin $\mathrm{A}$ 
221 regardless of $\mathrm{O}_{2}$ concentration (Figure $\mathrm{S5C}$ ). This suggests that BMDM acidification is

222 glycolytically-derived under both normoxia and hypoxia.

223

224 TR-AM cytokine production in response to LPS was highly susceptible to inhibition by low doses

225 of ETC inhibitors, rotenone and antimycin A, under normoxic conditions. This effect was greatly

226 attenuated after exposure to hypoxia (Figure 5D). Additionally, high doses of ETC inhibitors

227 induce cytotoxicity in normoxic TR-AMs, but hypoxic preconditioning significantly enhanced TR-

228 AM cell viability (Figure 5E). In contrast, BMDM cytokine production was only marginally affected

229 by ETC inhibition with the exception of observed decrease in IL-1 $\beta$. Unlike TR-AMs, hypoxia did 230 not significantly alter BMDM cytokine production in the presence of ETC inhibitors (Figure S5D).

231 Similarly, ETC inhibition did not to induce cytotoxicity in BMDMs under normoxia or hypoxia

232 (Figure S5E).

TR-AM survival correlates with a shift to glycolytic metabolism during influenza-induced

236 LPS is a well-known and potent macrophage activator that in isolation can be used to investigate

237 essential immune functions, such as cytokine production, signal transduction, and

238 immunometabolism. It induces a broad range of inflammatory effects in macrophages making it

239 convenient tool to study overall immune fitness in vitro. However, in vivo studies have shown that

240 LPS instillation into the murine airway leads to an immune response predominated by infiltrating

241 neutrophils making LPS-induced ALI an unsuitable model to study macrophages (Chignard and

242 Balloy 2000). Compared to LPS, influenza infection is a more clinically relevant model of ARDS,

243 and various macrophages populations play a larger role in both exacerbating and limiting lung

244 injury in this model (Short, Kroeze et al. 2014). Several groups have demonstrated that TR-AMs

245 undergo cell death in response to influenza infection and that depletion of TR-AMs is associated

246 with worse outcomes in models of influenza-induced ALI (Kim, Lee et al. 2008, Jaworska, 
247 Coulombe et al. 2014, Nelson, Zhou et al. 2014, Schneider, Nobs et al. 2014, Cardani, Boulton

248 et al. 2017). To confirm this phenomenon, we utilized PKH26 Red Fluorescent Linker dye to 249 specifically label, track, and collect TR-AMs over the time course of infection as we and others

250 have previously described (Maus, Herold et al. 2001, Maus, Grote et al. 2002, Woods, Kimmig et

251 al. 2020). In agreement with Zhu et al. (Zhu, Wu et al. 2021), we found that there was a significant

252 decrease in TR-AMs (PKH26+) at 3 (D3) and 6 (D6) days post infection along with a subsequent

253 increase in infiltrating, monocyte-derived alveolar macrophages (Mo-AMs) (Figure 6A). From

254 these experiments, we performed RNAseq on sorted TR-AMs (PKH26+) and Mo-AMs (PKH26-)

255 at D0, D3, and D6 (note: Mo-AMs are not present in an uninfected (D0) mouse)) to identify

256 changes in the metabolic gene signature of these two macrophage populations during influenza

257 infection. From D0 to D6, RNAseq data revealed that TR-AMs experienced decreased expression

258 in genes related to oxidative phosphorylation with simultaneous increased expression of genes

259 related to glycolytic metabolism. Moreover, the metabolic gene signature of D6 TR-AMs was most

260 similar to that of Mo-AMs at D3 and D6 (Figure 6B, C). Taken together, these data suggest that

261 influenza-induced ALI leads to a decrease in TR-AM number, and that the surviving TR-AMs'

262 gene signature shifts away from genes related to mitochondrial metabolism in favor of glycolysis.

264 HIF-1a stabilization increases TR-AM survival and improves outcomes in influenza-

265 induced acute lung injury

266 Given that the reduced TR-AM population on D6 presented with a glycolytic gene signature, we

267 hypothesized that TR-AM survival was dependent upon a metabolic shift to glycolysis. In other

268 words, a decrease in TR-AM numbers overtime was due to a large fraction of the cells failing to

269 metabolically adapt to the conditions of the infected/hypoxic alveoli. Thus, TR-AMs that could not

270 adapt to hypoxia and retained primarily mitochondria-driven metabolism died off while TR-AMs

271 that shifted to glycolytic metabolism survived. To test this hypothesis, we first sought to determine

272 if stabilization of HIF-1 $\alpha$ was sufficient to induce a hypoxic metabolic state in AMs without altering 
$273 \mathrm{O}_{2}$ levels. To do this, we treated cells with FG-4592, an inhibitor of HIF prolyl hydroxylases. FG-

2744592 has a greater potency and fewer off target effects compared to DMOG, which broadly inhibits

275 2-oxoglutarate-dependent oxygenases (Singh, Wilson et al. 2020). TR-AMs treated with FG-4592

276 for 16 hours experienced a significant dose-dependent increase in glycolysis. (Figure 7A, B). FG-

2774592 induced robust HIF-1a stabilization leading to increased expression of HK2, LDHA, PHD1,

278 and PHD3 (Figure 7C, D). Unlike hypoxia $\left(1.5 \% \mathrm{O}_{2}\right)$, FG-4592 had very little impact on overall

279 mitochondrial fitness in TR-AMs (Figure 7E). Basal respiration and mitochondrial ATP production

280 were reduced, but spare mitochondrial compacity was increased, signaling a shift toward

281 glycolytic ATP production at baseline but no loss in overall mitochondrial function (Figure 7E-G).

282 Like hypoxia, FG-4592 treatment could also rescue ETC inhibitor-induced impairment in cytokine 283 production (Figure $7 \mathrm{H}$ ) and cell death in TR-AMs (Figure 7I). However, unlike TR-AMs exposed

284 to $1.5 \% \mathrm{O}_{2}, \mathrm{FG}-4592$ did not broadly alter LPS cytokine responses suggesting that changes in

285 the cytokine profile under hypoxia are oxygen-dependent, but remain independent of HIF-1 $\alpha$ stabilization (Figure $7 \mathrm{H}$ ).

We next treated mice intratracheally with one dose of FG-4592 at the time of infection to evaluate the effect of early glycolytic adaptation on TR-AM survival and influenza-induced acute lung injury. Strikingly, FG-4592 treatment resulted in increased TR-AM (PKH26+ cells) survival at 6 days post

291 infection (dpi) compared to infected controls (Figure 8A). The increase in TR-AM survival in FG292 4592-treated mice was associated with reduced alveolar permeability (Figure 8B). FG-4592 293 treatment also led to a reduction in pro-inflammatory cytokine levels within the alveolar space at 294 6dpi (Figure 8C). Most importantly, FG-4592 treated mice experienced reduced weight loss and 295 improved survival compared to infected controls (Figure 8D, E). Taken to together, these data 296 suggest intratracheal FG-4592 treatment can increase TR-AM survival and improve outcomes in 297 influenza-infected mice. 


\section{DISCUSSION}

ARDS is associated with high morbidity and mortality. Despite many decades of research,

301 treatment remains supportive and there is no therapy that directly targets the pathogenesis of

302 ARDS. Infection is the main cause of ARDS. Respiratory viruses such as influenza A virus and

303 SARS-CoV-2 cause significant mortality by causing ARDS. In fact, the 2009 influenza pandemic

304 and the ongoing COVID19 pandemic have shown that acute respiratory illnesses can have a

305 profound effect on society in the $21^{\text {st }}$ Century. ARDS caused by influenza A and SARS-CoV-2

306 viruses is associated with loss of TR-AMs, that correlates with disease severity and mortality

307 (Ghoneim, Thomas et al. 2013, Liao, Liu et al. 2020, Grant, Morales-Nebreda et al. 2021, Zhu,

308 Wu et al. 2021). Because TR-AMs maintain a central role in lung homeostasis and response to

309 airborne pathogens, understanding basic TR-AM processes, like metabolic adaptation in

310 response to an altered lung environment during acute lung injury/ARDS, may allow us to

311 therapeutically rescue TR-AM cell death, and augment their function to improve outcomes in

312 acute respiratory illnesses.

314 We have previously demonstrated that TR-AMs are remarkably adapted to the high oxygen, low

315 glucose environment of the alveolar lumen and do not require glucose or glycolysis to carry out

316 their effector function as monocyte-derived macrophages do (Woods, Kimmig et al. 2020). ARDS

317 leads to significant hypoxia to which TR-AMs need to adapt; thus, we sought to determine whether

318 TR-AMs displayed metabolic plasticity during conditions of low oxygen. In this study, we found

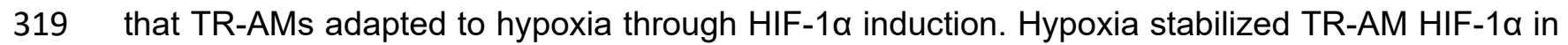

320 a dose-dependent manner resulting in robust increases in glycolytic protein expression and

321 function. These changes were dependent on HIF-1a, as hypoxic TR-AMs treated with

322 echinomycin, an inhibitor of HIF-1a DNA binding activity, lost their glycolytic capabilities. In

323 contrast, BMDMs exhibited robust HIF-1a stabilization under normoxic conditions and BMDM

324 HIF-1a expression and glycolytic output remained unchanged in response to hypoxia. 
325 Transcriptomic analysis found 741 DEGs in TR-AMs in response to hypoxia compared to only 326260 DEGs in BMDMs. Taken together, these data suggest that TR-AMs, although adapted to their

327 unique high oxygen and low glucose environment, are capable of using glycolytic metabolism

328 under stress conditions. Indeed, our in vivo experiments show that although TR-AMs are lost

329 during ARDS, the surviving TR-AMs are glycolytically adapted and resemble recruited

330 macrophages in metabolic gene expression. This is consistent with our previous findings that TR-

331 AM viability is exquisitely sensitive to mitochondrial inhibition while BMDM viability is unaffected.

332 Our current findings show that hypoxia restores viability to TR-AMs under mitochondrial inhibition

333 and reveres the suppressive effects of this inhibition on TR-AM cytokine production supporting

334 optimal effector function in a low oxygen environment. These data suggest that the link between

335 immune effector function and metabolism in TR-AMs is based on overall cellular fitness, and that

336 the environmental shift from high oxygen and low glucose under steady-conditions to low oxygen

337 and increased glucose during lung injury may necessitate cellular adaptation to the

338 microenvironment to ensure survival.

Pharmacological depletion of TR-AMs has offered insight into their beneficial immunoregulatory

341 properties in various lung injury models. TR-AMs have been shown to alleviate lung injury by

342 clearing apoptotic neutrophils, suppressing T-cell-mediated inflammatory responses, and limiting

343 dendritic cell infiltration and antigen presentation (Thepen, Van Rooijen et al. 1989, Holt, Oliver

344 et al. 1993, Knapp, Leemans et al. 2003, Jakubzick, Tacke et al. 2006). Loss of TR-AMs during

345 influenza infection is known to enhance mortality, and several studies have shown that there is a

346 progressive loss of TR-AMs over the time course of infection (Kim, Lee et al. 2008, Ghoneim,

347 Thomas et al. 2013, Schneider, Nobs et al. 2014, Cardani, Boulton et al. 2017, Zhu, Wu et al.

348 2021). Why TR-AMs are lost during the course of IAV infection is not understood. We

349 hypothesized that failure to adapt to the hypoxic environment may play a role in the TR-AM loss.

350 We found that HIF-1 $1 \alpha$ activation was sufficient to promote glycolysis, and rescue TR-AM viability 
351 and effector function under mitochondrial inhibition. Furthermore, when mice were treated with a

352 HIF-1a stabilizer at the time of influenza infection, TR-AM survival was increased, and

353 accompanied by reduced lung injury and death. These findings suggest that HIF-1a is essential

354 for TR-AM cell survival, and that increasing TR-AM cell number by promoting their adaptation to

355 ARDS associated changes in the microenvironment during infection reduces lung injury.

357 In agreement with our findings, Zhu and colleagues recently showed that TR-AMs at D6 of

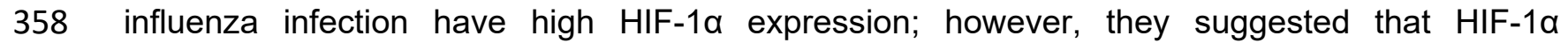
359 stabilization in TR-AMs worsens lung injury through enhanced proinflammatory effector function 360 (Zhu, Wu et al. 2021). This study relied on the use of a non-inducible Cd11c cre allele to knockout 361 HIF-1 $\alpha$ in TR-AMs. While TR-AMs do express high levels of Cd11c, this marker is not specific for 362 TR-AMs, and is also expressed in different monocyte/macrophage populations, dendritic cells, 363 and natural killer cells (Abram, Roberge et al. 2014). Moreover, as monocyte-derived macrophages enter the alveolar space, they begin to express Cd11c (Misharin, Morales-Nebreda et al. 2013). Thus, it cannot be determined from these experiments whether the observed effect of HIF-1a deletion on inflammation and lung injury was specific for TR-AMs as the recruited monocyte-derived macrophages will also lose HIF-1 $\alpha$ as they enter the lungs. It is likely that the recruitment of monocyte-derived macrophages was inhibited by HIF-1 $\alpha$ deletion, resulting in reduced inflammation and lung injury (Cramer, Yamanishi et al. 2003). Using FG-4592 in vitro, we found that HIF-1 $\alpha$ stabilization and glycolytic reprogramming resulted in no significant changes

371 in proinflammatory cytokine production downstream of LPS. Furthermore, we show that treatment 372 of mice with FG-4592 promoted survival of TR-AMs after influenza infection, and lead to reduced 373 levels of lung injury. An inducible model of HIF-1a activation will be required to conclusively 374 demonstrate whether HIF-1a expression specifically in TR-AMs promotes survival during lung 375 injury since constitutive activation of HIF-1a leads to defects in TR-AM development (Izquierdo, 376 Brandi et al. 2018). There have also been no studies on the effects of long-term HIF-1a activation 
377 and resultant metabolic reprogramming in TR-AMs under steady state or during recovery from

378 inflammatory stimuli. Thus, our short-term pharmacologic activation of HIF-1a and glycolytic

379 reprogramming in TR-AMs is a useful model for studying the role of metabolic reprogramming

380 during lung injury.

381

382 Interestingly, we found that the effects of hypoxia on both TR-AM and BMDM effector function

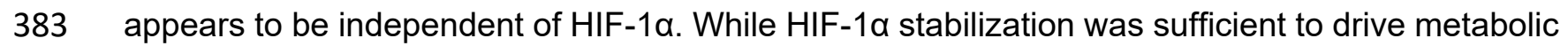
384 reprogramming in TR-AMs, FG-4592 did not affect cytokine production downstream of LPS. By 385 contrast, when cultured in hypoxia TR-AMs exhibited marked changes in their secreted cytokine 386 profile including increased secretion of TNF- $\alpha, \mathrm{KC}$, and IL-1 $\beta$ and less IL-6 and CCL2 compared 387 to normoxic controls. BMDMs exposed to hypoxia and treated with LPS responded similarly to 388 TR-AMs with the exception to CCL2, which remained unchanged in response to hypoxia in BMDMs. This was independent of any effect of hypoxia on HIF-1a stabilization or target gene expression in BMDMs. Similarities between TR-AMs and BMDMs in terms of cytokine profiles

391 would suggest that low oxygen concentrations may be driving these changes independently of 392 HIF-1a stabilization. Further investigation will be required to elucidate the mechanisms by which 393 a low oxygen environment alters cytokine production.

395 In conclusion, under normoxic conditions, TR-AMs depend on mitochondrial respiration, inhibition 396 of which leads to decreased effector response and cell death. Under hypoxic conditions, as occurs

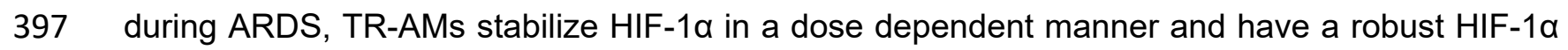
398 response compared to BMDMs. Stabilization of HIF-1a allows TR-AMs to augment glycolytic 399 function, and prevents their death following the inhibition of mitochondrial respiration as well as 400 following influenza A viral infection. These data suggest that therapies inducing HIF-1 $\alpha$ in TR401 AMs may be beneficial in ARDS by preventing their death through metabolic adaptation to the 402 ARDS microenvironment that is low in $\mathrm{O}_{2}$ and high in glucose. 


\section{MATERIALS AND METHODS}

\section{Primary Culture of Macrophages}

405 All studies in animals were approved by the Institutional Animal Care and Use Committee at the

406 University of Chicago IACUC. 6-8 week old C57BL/6 mice were humanely euthanized, and their

407 TR-AMs were isolated via standard bronchoalveolar lavage (intratracheal instillation) using PBS

$408+0.5 \mathrm{mM}$ EDTA. Following isolation, TR-AMs were counted, plated in RPMI 1640 (ThermoFisher,

409 catalog number 11875119) supplemented with 10\% FBS (Gemini, catalog number 100-106) and

$4101 \%$ penicillin-streptomycin (Gemini, catalog number 400-109), and allowed to adhere to tissue

411 culture plates for one hour prior to experimentation. BMDMs were generated by isolating bone

412 marrow cells from the femur and tibia bones of 6-8 week old C57BL/6 mice. Bone marrow cells

413 were differentiated into BMDMs using $40 \mathrm{ng} / \mathrm{mL}$ recombinant M-CSF (BioLegend, catalog number

414 576406) in the same media formulation as TR-AMs. On day seven, BMDMs were replated and

415 allowed to adhere to tissue culture plates for two hours prior to experimentation. After adherence,

416 cells were washed, fresh media added, and placed under experimental conditions. For

417 inflammatory stimulation, LPS was used at a concentration of $20 \mathrm{ng} / \mathrm{ml}$. For hypoxia experiments,

418 macrophage cultures were placed in an airtight incubator system that utilizes $\mathrm{N}_{2}$ displacement of

$419 \mathrm{O}_{2}$ to achieve hypoxic conditions (Coy Hypoxic Chamber- $\mathrm{O}_{2}$ Control InVitro Glove Box). The

420 sealed system ensures minimal fluctuations in $\mathrm{O}_{2}$ levels in experiments when treating cultures

421 and collecting samples under hypoxic conditions.

\section{Bioenergetic Measurements}

423 Glycolytic and mitochondrial respiration rates were measured using the XFe24 Extracellular Flux

424 Analyzer (Agilent, Santa Clara, MA). BMDMs and TR-AMs were seeded at $4.0 \times 10^{4} /$ well onto

425 Seahorse XF24 Cell Culture Microplates. Cells were equilibrated with XF Base media (Agilent,

426 catalog number $103334-100$ ) at $37^{\circ} \mathrm{C}$ for 30 minutes in the absence of $\mathrm{C} 02$. Glycolytic rate was

427 assessed using the manufacturers' protocol for the Seahorse XF Glycolysis Stress Test followed

428 by sequential injections with glucose $(10 \mathrm{mM})$, oligomycin $(1.0 \mu \mathrm{M})$, and 2-DG (100mM). 
429 Mitochondrial respiration rate was measured using the Seahorse XF Mito Stress Test according

430 to the manufacturer's protocol followed by sequential injections with oligomycin $(1.0 \mu \mathrm{M}), \mathrm{FCCP}$

$431(1.0 \mu \mathrm{M}$ for BMDMs and $4.0 \mu \mathrm{M}$ for TR-AMs), and rotenone/antimycin $\mathrm{A}(1.0 \mu \mathrm{M})$. Assessment of

432 real-time metabolic responses to LPS was performed using the protocol detailed in an application

433 note provided by the Agilent (Kam Y 2017). In brief, following plating, cells were equilibrated in

$434 \mathrm{XF}$ base media supplemented with $10 \mathrm{mM}$ glucose, $2 \mathrm{mM}$ L-glutamine, $1 \mathrm{mM}$ sodium pyruvate

435 (Sigma, catalog number 11360070) and 5 mM HEPES (Sigma, catalog number 15630080), pH

4367.4 and incubated at $37{ }^{\circ} \mathrm{C}$ without $\mathrm{CO} 2$ for 30 minutes prior to XF assay. Baseline metabolic

437 rates were measured followed by direct injection of LPS (final concentration:20ng/ml).

438 Bioenergetic rates were subsequently measured every three minutes for approximately 5 hours

439 in total.

440 Due to the limitations of the XFe24 Extracellular Flux Analyzer, all bioenergetic analysis on

441 hypoxic samples was performed in the following manner. Cells were treated under hypoxic

442 conditions (most commonly for 16 hours) then bioenergetic analysis was performed under

443 normoxic conditions. Moreover, it is impossible to evaluate varying levels of hypoxia on a single

444 Seahorse microplate. Thus, energy curves comparing varying levels of $\mathrm{O}_{2}$ (i.e. Figure $1 \mathrm{~A}$ ) were

445 performed individually and then subsequently represented on the same graph for comparison. All

446 individual experiments were repeated a minimum of three times to an ensure accurate

447 representation and statistical comparison.

448 Cell lysis, subcellular fractionalization and Immunoblotting

449 Whole cell lysates were prepared by scraping cells into lysis buffer containing $25 \mathrm{mM}$ Tris $\bullet \mathrm{HCl}(\mathrm{pH}$ 4507.6 ), $150 \mathrm{mM} \mathrm{NaCl}, 1 \% \mathrm{NP}-40,1 \%$ sodium deoxycholate, $0.1 \%$ SDS, $0.1 \%$ Benzonase, and 451 Halt ${ }^{\text {TM }}$ Protease Inhibitor Cocktail (ThermoFisher, catalog number 1861284 and 78430). Samples

452 were centrifuged at $16,000 \times \mathrm{g}$ at $4{ }^{\circ} \mathrm{C}$ for $5 \mathrm{~min}$ to pellet cellular debris. Subcellular 453 fractionalization and lysate preparation were carried out using the NE-PER Nuclear and 
454 Cytoplasmic Extraction Reagents (ThermoFisher, catalog number 78833). Lysate protein

455 concentration was determined using the Pierce ${ }^{\mathrm{TM}}$ BCA Protein Assay Kit (ThermoFisher, catalog

456 number 23225). Equal concentrations of samples (15 $\mathrm{g}$ for whole cell lysates and $5 \mu \mathrm{g}$ for nuclear

457 fractions) were resolved on Criterion gels (Bio-Rad, catalog number 5671093 and 5671094) and

458 transferred to nitrocellulose (Bio-Rad, catalog number 1620167). Primary antibodies used were

459 rabbit anti-HK2 (Cell signaling, catalog number C64G5, 1:1000), rabbit anti-LDHA (Cell signaling,

460 catalog number 20125, 1:1000), rabbit anti-PHD2/Egln1 (Cell Signaling, catalog number 4835,

461 1:1000), rabbit anti-Egln3/PHD3 (Novus Biologicals, catalog number NB100-303, 1:1000), mouse

462 anti-IL1 $\beta$ (Cell signaling, catalog number 12242 1:1000), rabbit anti-Lamin B1 (Proteintech,

463 catalog number 12987-1-AP, 1:1000), rabbit anti-HIF-1a (Caymen Chemical, catalog number

464 10006421, 1:500), and mouse anti-tubulin (Sigma, catalog number T6074, 1:20,000). Secondary

465 antibodies used were anti-rabbit lgG HRP-linked antibody (Cell Signaling, catalog number 7074,

466 1:2,500) and goat anti-mouse IgG HRP-linked antibody (Cell Signaling, catalog number 7076,

467 1:2,500). Protein expression was visualized using Immobilon ECL Ultra Western HRP Substrate

468 (Millipore Sigma, catalog number WBULS0500) in combination with the BioRad ChemiDoc Touch

469 Imaging system. All immunoblot data were repeated in at least three independent experiments.

\section{Quantitative PCR}

471 RNA was isolated from cells using the Direct-zol RNA MiniPrep kit (Zymo Research, catalog

472 number R2052) and reverse transcribed using iScript Reverse Transcription Supermix (Bio-Rad,

473 catalog number 1708841). Quantitative mRNA expression was determined by real-time RT-PCR

474 using iTaq Universal SYBR Green Supermix (Bio-Rad, catalog number 172-5121). rlp19 served

475 as a housekeeping gene, and gene expression was quantified using the $\Delta \Delta \mathrm{ct}$ method to determine

476 relative fold-change The following mouse-specific primer sequences were used: rlp19 (5'-

477 CCGACGAAAGGGTATGCTCA-3', 5'-GACCTTCTTTTTCCCGCAGC-3'), II6 (5'-

478 TTCCATCCAGTTGCCTTCTTGG-3', 5'-TTCCTATTTCCACGATTTCCCAG-3'), $\quad$ tnf $\alpha \quad\left(5^{\prime}-\right.$ 
AGGGGATTATGGCTCAGGGT-3',

5'-CCACAGTCCAGGTCACTGTC-3',

il1 $\beta$

$\left(5^{\prime}-\right.$

480 GCCACCTTTTGACAGTGATGAG,

5'-GACAGCCCAGGTCAAAGGTT-3'), $\quad k c$

$(5 '-$

481

AGACCATGGCTGGGATTCAC-3',

5'-ATGGTGGCTATGACTTCGGT-3'),

$\mathrm{ccl} 2$

$\left(5^{\prime}-\right.$

482 CTGTAGTTTTTGTCACCAAGCTCA-3', 5'-GTGCTGAAGACCTTAGCCCA-3').

\section{RNA-Sequencing}

RNA was isolated and submitted to the University of Chicago Genomics Core Facility for sequencing with the Illumina NovaSEQ6000 sequencer (100bp paired-end). Sequencing read (FASTQ) files were generated and assessed for per base sequence quality using FastQC. Reads were mapped to the mouse genome (GRCm38.p6, GENCODE) using Spliced Transcripts Alignment to a Reference (STAR) software, and the resulting gene transcripts were quantified using featureCounts.

491 Gene counts were then imported into R for differential expression analysis using the Bioconductor

492 package DESeq2. Gene counts were filtered to remove low-expressing genes at a threshold of 2 493 counts per million. Differential expression was calculated between normoxia and hypoxia groups

494 for both AMs and BMDMs. Differential gene expression was considered significant for genes with 495 an FDR-adjusted $p$-value $<0.05$ and fold change $(F C)>2$. Reactome enrichment hit pathways 496 and the linked gene lists from significant DEGs were identified by using Reactome Cytoscape

497 Plugin (Shannon, Markiel et al. 2003, Wu, Feng et al. 2010). Oxidative phosphorylation and 498 glycolysis gene sets were extracted from UniProtKB, then their associated DEG read counts 499 (TPM) were normalized using gensvm R package gensvm.maxabs.scale function and center 500 scaled for heat map visualization. All heatmaps were generated with Pretty heatmaps R package 501 pheatmap function.

\section{Cytokine Analysis}

503 Secreted TNF $\alpha, \mathrm{IL}-6, \mathrm{KC}, \mathrm{CCl} 2$, and IL-1 $\beta$ levels were evaluated in macrophage media using a 
504 standard sandwich ELISA (R\&D Systems DuoSet ELISA Development System, catalog numbers

505 DY410, DY406, DY453, DY479 and DY401). For IL-1 $\beta$ sample collection, 5mM ATP was added

506 to TR-AM cultures for 30 minutes following $6 \mathrm{~h}$ LPS treatment to activate caspase 1 , ensuring

507 prolL-1 $\beta$ cleavage and IL-1 $\beta$ release. Rotenone and Antimycin A concentrations were 20nM for

508 TR-AMs and $1 \mu \mathrm{M}$ for BMDMs when used in ELISA experiments.

509 Metabolomics

510 TR-AMs were plated at $2.5 \times 10^{6}$ on $60 \mathrm{~mm}$ plates for metabolite extraction. Following treatment, 511 cells were washed twice with a $5 \%$ mannitol solution and metabolites were extracted using $400 \mu l$

$512100 \%$ methanol. $275 \mu$ l of aqueous internal standard solution was mixed in with the methanol and

513 the extract solution was transferred to a microcentrifuge. The extracts underwent centrifugation

514 at $2,300 \times g$ at $4{ }^{\circ} \mathrm{C}$ for $5 \mathrm{~min}$ to precipitate insoluble material and the resulting supernatant was

515 transferred to centrifugal filter units (Human Metabolome Technologies (HMT), Boston, MA).

516 Filtering of supernatant occurred at $9,100 \times g$ at $4{ }^{\circ} \mathrm{C}$ for 2 hours. The filtrate was sent to HMT

517 and analyzed using capillary electrophoresis-mass spectrometry.

518 Sulforhodamine B (SRB) Colorimetric Assay

519 In vitro cytotoxicity was measured using the SRB assay (Vichai and Kirtikara 2006). Following 520 treatment, cells were fixed in 10\% TCA and then stained with SRB dye. Cellular protein-dye 521 complexes were solubilized in $10 \mathrm{mM}$ Tris base and the samples were read at OD 510 using a 522 microplate reader. Data was normalized to the untreated, normoxia groups, which were 523 representative of no cellular damage. ETC inhibitor concentration in BMDMs were as follows: $1 \mu \mathrm{M}$ 524 rotenone, and $1 \mu \mathrm{M}$ antimycin $\mathrm{A}$. ETC inhibitor concentration in TR-AMs were as follows: $500 \mathrm{nM}$ 525 rotenone, and $100 \mathrm{nM}$ antimycin $\mathrm{A}$.

\section{Lactate Assay}

527 Secreted lactate was measured using the lactate colorimetric assay kit (Sigma, catalog number 528 MAK064-1KT). Cells were plated in serum-free DMEM media (RPMI media and serum interfere 
529 with assay), allowed to adhere, washed with phosphate buffer saline, and exposed to normoxia

530 or $1.5 \% \mathrm{O}_{2}$. Samples were collected at 16 hours post treatment and manufacturer's protocol was

531 followed to measure

532 lactate.

\section{Murine Influenza infection protocol and Survival Studies}

534 C57BL/6 mice (6-8 weeks old) were anesthetized and challenged intratracheally (IT) with mouse535 adapted influenza (A/PR8/34; 200 plaque-forming units [pfu]). A single FG-4592 (50uM) treatment

536 was administered (IT) simultaneously with IAV. Body weight and survival was monitored every 24

537 hours for 20 days (10 mice/group). Body weight is represented as percent deviation from baseline

538 at time of infection. "Influenza A virus, A/PR8/34 (H1N1), NR-348" was obtained through BEI

539 Resources, NIAID, NIH.

540 BALF analysis

$541 \mathrm{C} 57 \mathrm{BL} / 6$ mice were euthanized and a single $0.5 \mathrm{ml}$ saline wash was instilled into the lungs via the

542 trachea and subsequently collected. BALF protein concentration was determined using the

543 Pierce $^{\mathrm{TM}}$ BCA Protein Assay Kit (ThermoFisher, catalog number 23225). BALF TNF $\alpha$, IL-6, and

$544 \quad$ IL-1 $\beta$ were measured using sandwich ELISA.

\section{Flow Cytometry}

546 C57BL/6 mice (6-8 weeks old) were anesthetized with isoflurane and underwent retro-orbital

547 injection with $100 \mu \mathrm{l}$ PKH26 Red Fluorescent Cell Linker Dye for Phagocytic Cell Labeling (catalog

548 number PKH26PCL-1KT; Millipore Sigma) 1 day before lung challenge. The mice were then

549 challenged intratracheally with IAV 100 (pfu). FG-4592 $(50 \mu \mathrm{M})$ was administered intratracheally

550 at the same time of PR8 infection. After challenge, the mice were euthanized and immune cells

551 were collected via BAL. BAL cells were first treated with Fc Block (clone 2.4G2, catalog number

552 553141; BD Biosciences) and stained with fluorochrome-conjugated antibodies. The antibodies

553 used were AlexaFluor 700 anti-mouse Ly-6G (Clone 1A8, catalog number 127621, 1:250; 
554 BioLegend). Immediately before sorting, cells were resuspended in sorting buffer $(0.2 \%$ BSA in

555 PBS) containing 5 nM SYTOX Green Nucleic Acid Stain (catalog number S7020; ThermoFisher)

556 to distinguish between live and dead cells. Cell sorting was performed on a FACS Aria II

557 instrument and data were acquired using BDFACS Diva software and analyzed with FCS Express

5587 software. First, debris, red blood cells, and lymphocytes were eliminated based on size (FSC)

559 and granularity (SSC). Next gates selected for live cells (FITC-) and eliminated neutrophils

560 (Ly6G+). Based on previous validation experiments, the remaining cells are of macrophage

561 lineage with TR-AMs being PKH26+ (SiglecF+,F4/80+,Cd11c $\left.{ }^{\mathrm{Hi}}, \mathrm{Ly}_{6} \mathrm{c}^{\mathrm{Lo}}\right)$ and Mo-AMs being

$562 \mathrm{PKH} 26-\left(\mathrm{F} 4 / 80+, \mathrm{Cd} 11 \mathrm{c}^{\mathrm{Lo}}, \mathrm{Ly} 6 \mathrm{c}^{\mathrm{Hi}}\right) . \mathrm{PKH} 26+$ and $\mathrm{PKH} 26-$ cells were sorted into RNA lysis buffer

563 and samples were prepared for RNAseq.

564 Statistics

565 The data were analyzed in Prism 8 (GraphPad Software Inc.). All data are shown as mean \pm SD.

566 ANOVA was used for statistical analyses of data sets containing more than two groups, and

567 Bonferroni's post hoc test was used to explore individual differences. Statistical significance was

568 defined as $P<0.05$. 
bioRxiv preprint doi: https://doi.org/10.1101/2022.02.28.482301; this version posted March 1, 2022. The copyright holder for this preprint

(which was not certified by peer review) is the author/funder, who has granted bioRxiv a license to display the preprint in perpetuity. It is made available under aCC-BY-NC-ND 4.0 International license.

\section{ACKNOWLEDGEMENTS}

570 Funding: T32HL007605 (PSW, LMK, ORS, GMM), R01HL151680 (RBH) and R01ES010524,

571 U01ES026718, P01HL144454, and Department of Defense W81XWH-16-1-0711 (GMM).

572

573 COMPETING INTERESTS

574 PSW, RBH and GMM have a pending patent on targeting tissue-resident alveolar macrophage

575 metabolism to prevent their death during ARDS. Otherwise, the authors do not have any 576 competing interests. 


\section{REFERENCES}

Abram, C. L., G. L. Roberge, Y. Hu and C. A. Lowell (2014). "Comparative analysis of the efficiency and specificity of myeloid-Cre deleting strains using ROSA-EYFP reporter mice." Journal of immunological methods 408: 89-100.

Baker, E. H. and D. L. Baines (2018). "Airway Glucose Homeostasis: A New Target in the Prevention and Treatment of Pulmonary Infection." Chest 153(2): 507-514.

Baker, E. H., N. Clark, A. L. Brennan, D. A. Fisher, K. M. Gyi, M. E. Hodson, B. J. Philips, D. L. Baines and D. M. Wood (2007). "Hyperglycemia and cystic fibrosis alter respiratory fluid glucose concentrations estimated by breath condensate analysis." Journal of Applied Physiology 102(5): 1969-1975.

Beck-Schimmer, B., R. Schwendener, T. Pasch, L. Reyes, C. Booy and R. C. Schimmer (2005). "Alveolar macrophages regulate neutrophil recruitment in endotoxin-induced lung injury." Respiratory research 6(1): 61-61.

Bosco, M. C., M. Puppo, C. Santangelo, L. Anfosso, U. Pfeffer, P. Fardin, F. Battaglia and L. Varesio (2006). "Hypoxia Modifies the Transcriptome of Primary Human Monocytes: Modulation of Novel Immune-Related Genes and Identification Of CC-Chemokine Ligand 20 as a New Hypoxia-Inducible Gene." The Journal of Immunology 177(3): 1941-1955.

Campbell, Eric L., Walter J. Bruyninckx, Caleb J. Kelly, Louise E. Glover, Eóin N. McNamee, Brittelle E. Bowers, Amanda J. Bayless, M. Scully, Bejan J. Saeedi, L. Golden-Mason, Stefan F. Ehrentraut, Valerie F. Curtis, A. Burgess, John F. Garvey, A. Sorensen, R. Nemenoff, P. Jedlicka, Cormac T. Taylor, Douglas J. Kominsky and Sean P. Colgan (2014). "Transmigrating Neutrophils Shape the Mucosal Microenvironment through Localized Oxygen Depletion to Influence Resolution of Inflammation." Immunity 40(1): 66-77.

Cardani, A., A. Boulton, T. S. Kim and T. J. Braciale (2017). "Alveolar Macrophages Prevent Lethal Influenza Pneumonia By Inhibiting Infection Of Type-1 Alveolar Epithelial Cells." PLOS Pathogens 13(1): e1006140.

Carreau, A., B. El Hafny-Rahbi, A. Matejuk, C. Grillon and C. Kieda (2011). "Why is the partial oxygen pressure of human tissues a crucial parameter? Small molecules and hypoxia." Journal of cellular and molecular medicine 15(6): 1239-1253.

Chignard, M. and V. Balloy (2000). "Neutrophil recruitment and increased permeability during acute lung injury induced by lipopolysaccharide." American Journal of Physiology-Lung Cellular and Molecular Physiology 279(6): L1083-L1090.

Cramer, T., Y. Yamanishi, B. E. Clausen, I. Förster, R. Pawlinski, N. Mackman, V. H. Haase, R. Jaenisch, M. Corr, V. Nizet, G. S. Firestein, H. P. Gerber, N. Ferrara and R. S. Johnson (2003). "HIF-1alpha is essential for myeloid cell-mediated inflammation." Cell 112(5): 645-657.

Delprat, V., C. Tellier, C. Demazy, M. Raes, O. Feron and C. Michiels (2020). "Cycling hypoxia promotes a pro-inflammatory phenotype in macrophages via JNK/p65 signaling pathway." Scientific reports 10(1): 882-882. 
627

628

629

630

631

632

633

634

635

636

637

638

639

640

641

642

643

644

645

646

647

648

649

650

651

652

653

654

655

656

657

658

659

660

661

662

663

664

665

666

667

668

669

670

671

672

673

674

675

676

677

Fan, E. K. Y. and J. Fan (2018). "Regulation of alveolar macrophage death in acute lung inflammation." Respiratory research 19(1): 50-50.

Freemerman, A. J., A. R. Johnson, G. N. Sacks, J. J. Milner, E. L. Kirk, M. A. Troester, A. N. Macintyre, P. Goraksha-Hicks, J. C. Rathmell and L. Makowski (2014). "Metabolic reprogramming of macrophages: glucose transporter 1 (GLUT1)-mediated glucose metabolism drives a proinflammatory phenotype." The Journal of biological chemistry 289(11): 7884-7896.

Fröhlich, S., J. Boylan and P. McLoughlin (2013). "Hypoxia-Induced Inflammation in the Lung." American Journal of Respiratory Cell and Molecular Biology 48(3): 271-279.

Ghoneim, H. E., P. G. Thomas and J. A. McCullers (2013). "Depletion of Alveolar Macrophages during Influenza Infection Facilitates Bacterial Superinfections." The Journal of Immunology 191(3): 1250.

Grant, R. A., L. Morales-Nebreda, N. S. Markov, S. Swaminathan, M. Querrey, E. R. Guzman, D. A. Abbott, H. K. Donnelly, A. Donayre, I. A. Goldberg, Z. M. Klug, N. Borkowski, Z. Lu, H. Kihshen, Y. Politanska, L. Sichizya, M. Kang, A. Shilatifard, C. Qi, J. W. Lomasney, A. C. Argento, J. M. Kruser, E. S. Malsin, C. O. Pickens, S. B. Smith, J. M. Walter, A. E. Pawlowski, D. Schneider, P. Nannapaneni, H. Abdala-Valencia, A. Bharat, C. J. Gottardi, G. R. S. Budinger, A. V. Misharin, B. D. Singer, R. G. Wunderink, R. A. Grant, L. Morales-Nebreda, N. S. Markov, S. Swaminathan, M. Querrey, E. R. Guzman, D. A. Abbott, H. K. Donnelly, A. Donayre, I. A. Goldberg, Z. M. Klug, N. Borkowski, Z. Lu, H. Kihshen, Y. Politanska, L. Sichizya, M. Kang, A. Shilatifard, C. Qi, J. W. Lomasney, A. C. Argento, J. M. Kruser, E. S. Malsin, C. O. Pickens, S. B. Smith, J. M. Walter, A. E. Pawlowski, D. Schneider, P. Nannapaneni, H. Abdala-Valencia, A. Bharat, C. J. Gottardi, G. R. S. Budinger, A. V. Misharin, B. D. Singer, R. G. Wunderink, A. A. Wagh, A. R. Hauser, A. R. Wolfe, A. Thakrar, A. V. Yeldandi, A. A. Wang, A. R. Levenson, A. M. Joudi, B. Tran, C. A. Gao, C. Kurihara, C. J. Schroedl, C. M. Horvath, D. Meza, D. D. Odell, D. W. Kamp, D. R. Winter, E. A. Ozer, E. D. Shanes, E. T. Bartom, E. J. Rendleman, E. M. Leibenguth, F. Wehbe, G. Y. Liu, G. T. Gadhvi, H. T. Navarro, J. I. Sznajder, J. E. Dematte, J. Le, J. M. Arnold, J. C. Du, J. Coleman, J. I. Bailey, J. S. Deters, J. A. Fiala, J. Starren, K. M. Ridge, K. Secunda, K. Aren, K. L. Gates, K. Todd, L. D. Gradone, L. N. Textor, L. F. Wolfe, L. L. Pesce, L. A. Nunes Amaral, M. L. Rosenbaum, M. Kandpal, M. Jain, M. A. Sala, M. Saine, M. Carns, M. J. Alexander, M. J. Cuttica, M. H. Prickett, N. H. Khan, N. S. Chandel, N. D. Soulakis, O. R. Rivas, P. C. Seed, P. A. Reyfman, P. D. Go, P. H. S. Sporn, P. R. Cooper, R. Tomic, R. Patel, R. Garza-Castillon, R. Kalhan, R. I. Morimoto, R. J. Mylvaganam, S. S. Kim, S. W. M. Gatesy, S. Thakkar, S. Ben Maamar, S. Han, S. R. Rosenberg, S. Nozick, S. J. Green, S. R. Russell, T. A. Poor, T. J. Zak, T. A. Lombardo, T. Stoeger, T. Shamaly, Z. Ren and N. U. S. S. I. The (2021). "Circuits between infected macrophages and T cells in SARS-CoV-2 pneumonia." Nature 590(7847): 635-641.

Holt, P. G., J. Oliver, N. Bilyk, C. McMenamin, P. G. McMenamin, G. Kraal and T. Thepen (1993). "Downregulation of the antigen presenting cell function(s) of pulmonary dendritic cells in vivo by resident alveolar macrophages." Journal of Experimental Medicine 177(2): 397-407.

Hussell, T. and T. J. Bell (2014). "Alveolar macrophages: plasticity in a tissue-specific context." Nature Reviews Immunology 14(2): 81-93.

Ip, W. K. E., N. Hoshi, D. S. Shouval, S. Snapper and R. Medzhitov (2017). "Anti-inflammatory effect of IL-10 mediated by metabolic reprogramming of macrophages." Science (New York, N.Y.) 356(6337): 513-519. 
678

679

680

681

682

683

684

685

686

687

688

689

690

691

692

693

694

695

696

697

698

699

700

701

702

703

704

705

706

707

708

709

710

711

712

713

714

715

716

717

718

719

720

721

722

723

724

725

726

727

728

Izquierdo, H. M., P. Brandi, M.-J. Gómez, R. Conde-Garrosa, E. Priego, M. Enamorado, S. Martínez-Cano, I. Sánchez, L. Conejero, D. Jimenez-Carretero, S. Martín-Puig, M. Guilliams and D. Sancho (2018). "Von Hippel-Lindau Protein Is Required for Optimal Alveolar Macrophage Terminal Differentiation, Self-Renewal, and Function." Cell reports 24(7): 17381746.

Jakubzick, C., F. Tacke, J. Llodra, N. van Rooijen and G. J. Randolph (2006). "Modulation of Dendritic Cell Trafficking to and from the Airways." The Journal of Immunology 176(6): 35783584.

Jaworska, J., F. Coulombe, J. Downey, F. Tzelepis, K. Shalaby, I. Tattoli, J. Berube, S. Rousseau, J. G. Martin, S. E. Girardin, J. A. McCullers and M. Divangahi (2014). "NLRX1 prevents mitochondrial induced apoptosis and enhances macrophage antiviral immunity by interacting with influenza virus PB1-F2 protein." Proc Natl Acad Sci U S A 111(20): E2110-2119.

Kam Y, S. P., Dranka BP (2017). "Real time discrimination of inflammatory macrophage activation using Agilent Seahorse XF technology (white paper)."

Kim, H. M., Y. W. Lee, K. J. Lee, H. S. Kim, S. W. Cho, N. van Rooijen, Y. Guan and S. H. Seo (2008). "Alveolar macrophages are indispensable for controlling influenza viruses in lungs of pigs." J Virol 82(9): 4265-4274.

Knapp, S., J. C. Leemans, S. Florquin, J. Branger, N. A. Maris, J. Pater, N. v. Rooijen and T. v. d. Poll (2003). "Alveolar Macrophages Have a Protective Antiinflammatory Role during Murine Pneumococcal Pneumonia." American Journal of Respiratory and Critical Care Medicine 167(2): 171-179.

Kong, D., E. J. Park, A. G. Stephen, M. Calvani, J. H. Cardellina, A. Monks, R. J. Fisher, R. H. Shoemaker and G. Melillo (2005). "Echinomycin, a Small-Molecule Inhibitor of HypoxiaInducible Factor-1 DNA-Binding Activity." Cancer Research 65(19): 9047-9055.

Lavin, Y., D. Winter, R. Blecher-Gonen, E. David, H. Keren-Shaul, M. Merad, S. Jung and I. Amit (2014). "Tissue-resident macrophage enhancer landscapes are shaped by the local microenvironment." Cell 159(6): 1312-1326.

Liao, M., Y. Liu, J. Yuan, Y. Wen, G. Xu, J. Zhao, L. Cheng, J. Li, X. Wang, F. Wang, L. Liu, I. Amit, S. Zhang and Z. Zhang (2020). "Single-cell landscape of bronchoalveolar immune cells in patients with COVID-19." Nature Medicine 26(6): 842-844.

Machado-Aranda, D., M. V Suresh, B. Yu, V. Dolgachev, M. R. Hemmila and K. Raghavendran (2014). "Alveolar macrophage depletion increases the severity of acute inflammation following nonlethal unilateral lung contusion in mice." The journal of trauma and acute care surgery 76(4): 982-990.

Matak, P., M. Heinis, J. R. R. Mathieu, R. Corriden, S. Cuvellier, S. Delga, R. Mounier, A. Rouquette, J. Raymond, D. Lamarque, J.-F. Emile, V. Nizet, E. Touati and C. Peyssonnaux (2015). "Myeloid HIF-1 Is Protective in \&lt;em\&gt;Helicobacter pylori\&lt;/em\&gt;-Mediated Gastritis." The Journal of Immunology 194(7): 3259.

Maus, U., K. v. Grote, W. A. Kuziel, M. Mack, E. J. Miller, J. Cihak, M. Stangassinger, R. Maus, D. Schlöndorff, W. Seeger and J. Lohmeyer (2002). "The Role of CC Chemokine Receptor 2 in 
Alveolar Monocyte and Neutrophil Immigration in Intact Mice." American Journal of Respiratory and Critical Care Medicine 166(3): 268-273.

731

Maus, U., S. Herold, H. Muth, R. Maus, L. Ermert, M. Ermert, N. Weissmann, S. Rosseau, W. Seeger, F. Grimminger and J. Lohmeyer (2001). "Monocytes recruited into the alveolar air space of mice show a monocytic phenotype but upregulate CD14." American Journal of Physiology-Lung Cellular and Molecular Physiology 280(1): L58-L68.

McQuattie-Pimentel, A. C., Z. Ren, N. Joshi, S. Watanabe, T. Stoeger, M. Chi, Z. Lu, L. Sichizya, R. P. Aillon, C.-I. Chen, S. Soberanes, Z. Chen, P. A. Reyfman, J. M. Walter, K. R. Anekalla, J. M. Davis, K. A. Helmin, C. E. Runyan, H. Abdala-Valencia, K. Nam, A. Y. Meliton, S. Chandel, J. I. Sznajder, W. E. Balch, B. D. Singer, A. V. Misharin and G. R. S. Budinger (2021). "The lung microenvironment shapes a dysfunctional response of alveolar macrophages in aging." The Journal of clinical investigation 131(4): e140299.

Misharin, A. V., L. Morales-Nebreda, G. M. Mutlu, G. R. S. Budinger and H. Perlman (2013). "Flow cytometric analysis of macrophages and dendritic cell subsets in the mouse lung." American journal of respiratory cell and molecular biology 49(4): 503-510.

Nelson, B., X. Zhou, M. White, K. Hartshorn, K. Takahashi, T. B. Kinane, A. Anandaiah and H. Koziel (2014). "Recombinant human mannose-binding lectin dampens human alveolar macrophage inflammatory responses to influenza A virus in vitro." J Leukoc Biol 95(5): 715-722.

Palsson-McDermott, E. M., A. M. Curtis, G. Goel, M. A. Lauterbach, F. J. Sheedy, L. E. Gleeson, M. W. van den Bosch, S. R. Quinn, R. Domingo-Fernandez, D. G. Johnston, J. K. Jiang, W. J. Israelsen, J. Keane, C. Thomas, C. Clish, M. Vander Heiden, R. J. Xavier and L. A. O'Neill (2015). "Pyruvate kinase M2 regulates Hif-1 $\alpha$ activity and IL-1 $\beta$ induction and is a critical determinant of the warburg effect in LPS-activated macrophages." Cell Metab 21(1): 65-80.

Peyssonnaux, C., V. Datta, T. Cramer, A. Doedens, E. A. Theodorakis, R. L. Gallo, N. HurtadoZiola, V. Nizet and R. S. Johnson (2005). "HIF-1alpha expression regulates the bactericidal capacity of phagocytes." The Journal of clinical investigation 115(7): 1806-1815.

Roiniotis, J., H. Dinh, P. Masendycz, A. Turner, C. L. Elsegood, G. M. Scholz and J. A. Hamilton (2009). "Hypoxia Prolongs Monocyte/Macrophage Survival and Enhanced Glycolysis Is Associated with Their Maturation under Aerobic Conditions." The Journal of Immunology 182(12): 7974-7981.

Schneider, C., S. P. Nobs, A. K. Heer, M. Kurrer, G. Klinke, N. van Rooijen, J. Vogel and M. Kopf (2014). "Alveolar Macrophages Are Essential for Protection from Respiratory Failure and Associated Morbidity following Influenza Virus Infection." PLOS Pathogens 10(4): e1004053.

Semenza, G. L. (2012). "Hypoxia-inducible factors in physiology and medicine." Cell 148(3): 399-408.

Shannon, P., A. Markiel, O. Ozier, N. S. Baliga, J. T. Wang, D. Ramage, N. Amin, B. Schwikowski and T. Ideker (2003). "Cytoscape: a software environment for integrated models of biomolecular interaction networks." Genome research 13(11): 2498-2504. 
Short, K. R., E. J. B. V. Kroeze, R. A. M. Fouchier and T. Kuiken (2014). "Pathogenesis of 
Fiqure 1 bioRxiv preprint doi: https://doi.org/10.1101/2022.02.28.482301; this version posted March 1, 2022. The copyright holder for this preprint (which was not certified by peer review) is the author/funder, who has granted bioRxiv a license to display the preprint in perpetuity. It is made available under aCC-BY-NC-ND 4.0 International license.

A

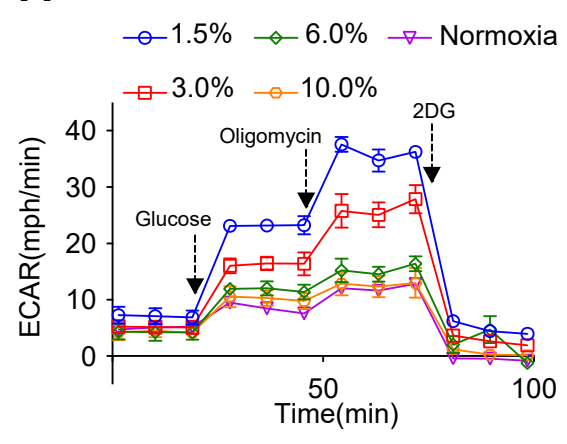

C

$\mathbf{F}$
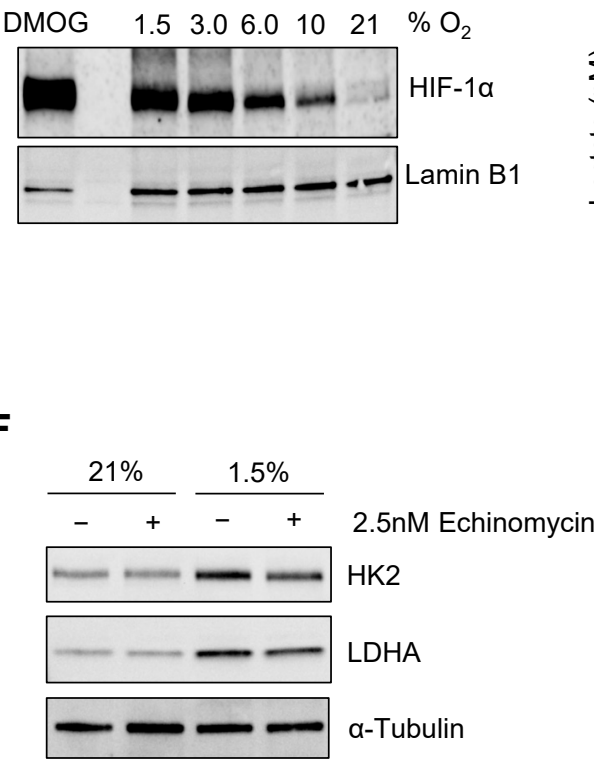

B
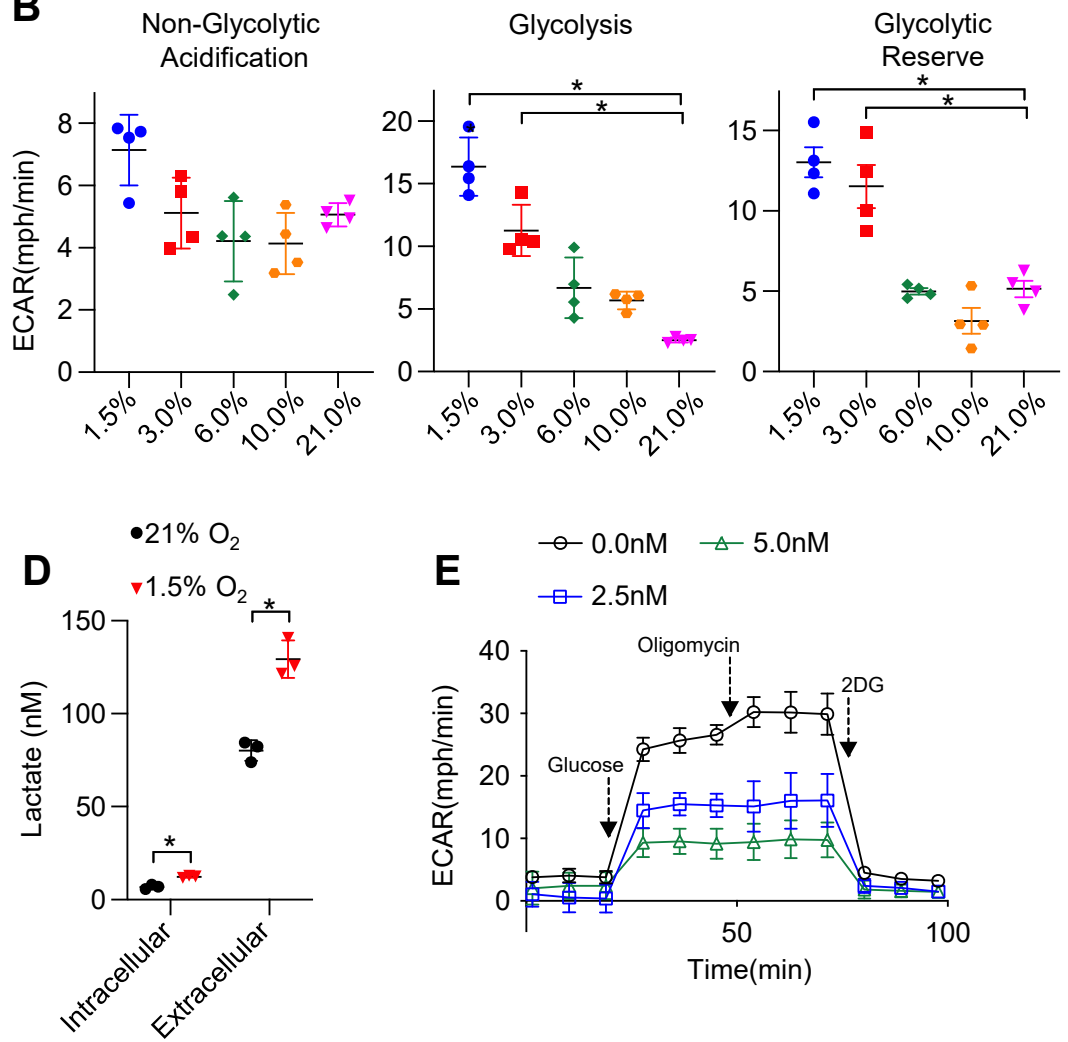

Figure 1. Tissue-resident alveolar macrophages exhibit HIF-1a stabilization and develop a glycolytic phenotype in response to hypoxia. TR-AMs were incubated overnight (16h) at varying $\mathrm{O}_{2}$ concentrations. (A) Using Seahorse XF24 analyzer, glycolysis was measured as extracellular acidification rate (ECAR). TR-AMs were sequentially treated with glucose, oligomycin (ATP synthase inhibitor) and 2-deoxyglucose (2-DG) (inhibitor of hexokinase 2, or glycolysis). (B) Interleaved scatter plots quantifying glycolytic parameters. Data represent at least 3 independent experiments ( $n=4$ separate wells per group). Glycolytic parameters were compared against $21 \% \mathrm{O}_{2}$ and significance was determined by one-way ANOVA with Bonferroni's post test. (C) Western blot analysis of nuclear extract to assess HIF-1 1 expression. DMOG served as a positive control (D) Extracellular and intracellular lactate levels in TR-AMs incubated overnight (16h) under normoxia or $1.5 \% \mathrm{O}_{2}$. Significance was determined by two-way ANOVA with Bonferroni's post test. (E) Glycolysis stress test of TR-AMs under $1.5 \% \mathrm{O}_{2}$ in combination with echinomycin (16h). (F) Western blot analysis of whole cell TR-AM extract after $16 \mathrm{~h}$ treatment. All error bars denote mean \pm SD. ${ }^{*}, p<0.05$ 
Fiqure 2 bioRxiv preprint doi: https://doi.org/10.1101/2022.02.28.482301; this version posted March 1, 2022. The copyright holder for this preprint (which was not certified by peer review) is the author/funder, who has granted bioRxiv a license to display the preprint in perpetuity. It is made available under aCC-BY-NC-ND 4.0 International license.

A

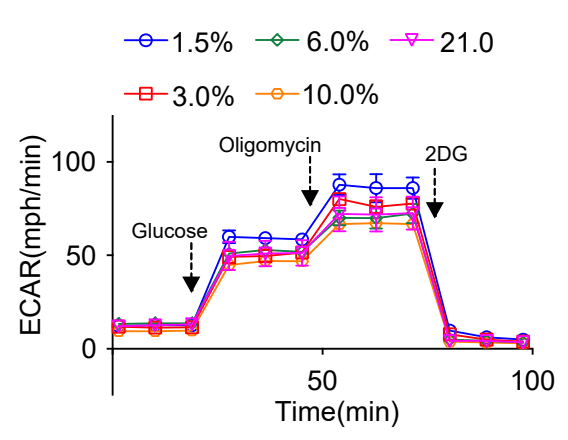

C

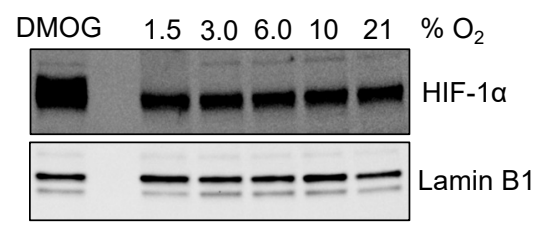

$\mathbf{F}$
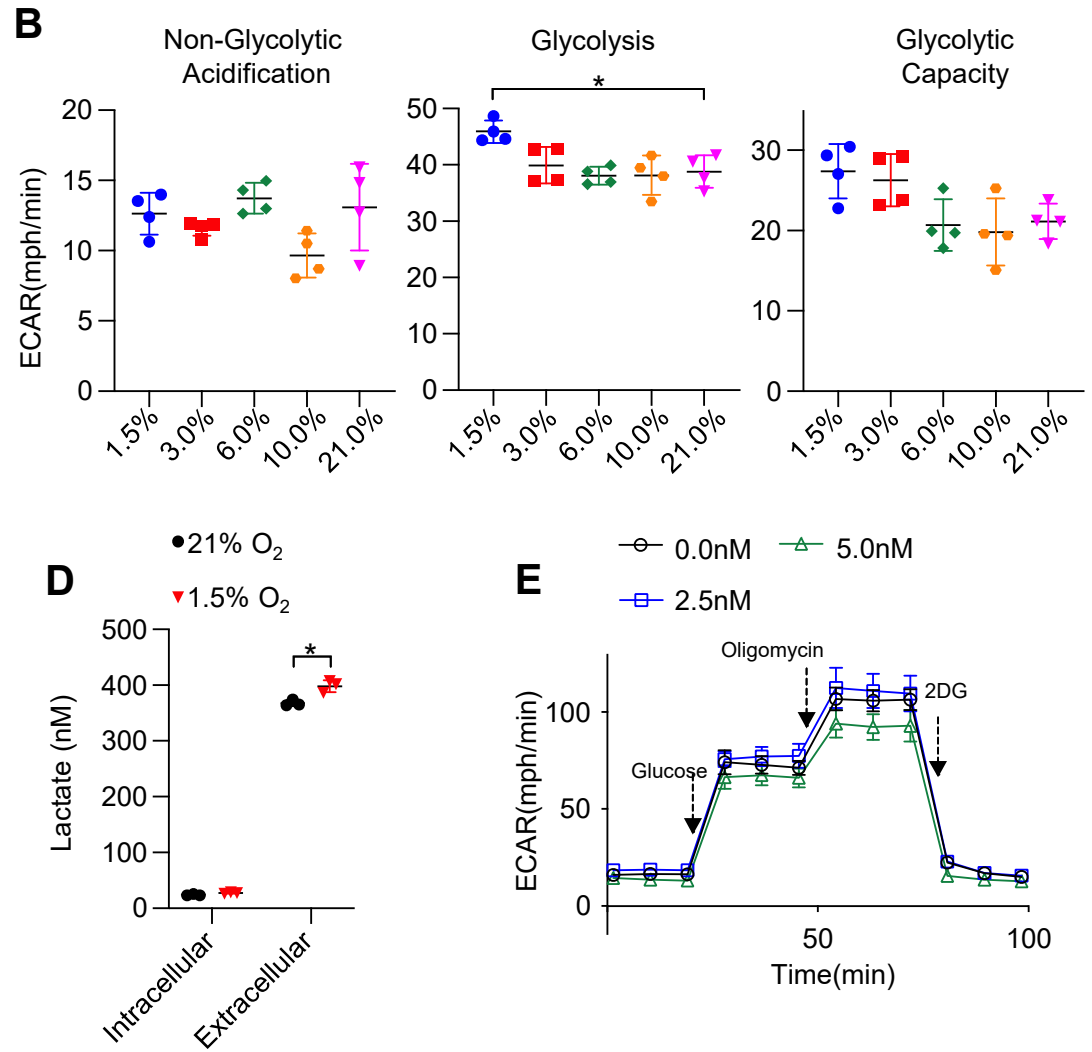

E $\quad-0.0 \mathrm{nM} \rightarrow 5.0 \mathrm{nM}$

E $\square 2.5 \mathrm{nM}$

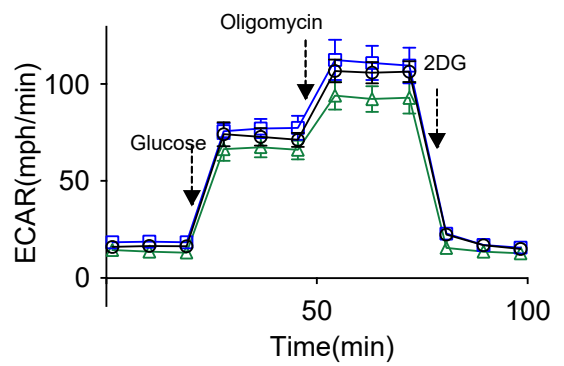

Figure 2. BMDMs have limited metabolic adaptation to hypoxia. BMDMs were incubated overnight (16h) at varying $\mathrm{O}_{2}$ concentrations. (A) Using Seahorse XF24 technology, glycolysis was measured as extracellular acidification rate (ECAR). (B) Interleaved scatter plots quantifying glycolytic parameters. Data represent at least 3 independent experiments ( $n=4$ separate wells per group). Glycolytic parameters were compared against $21 \% \mathrm{O}_{2}$ and significance was determined by one-way ANOVA with Bonferroni's post test. (C) Western blot analysis of nuclear extracts to assess HIF-1 $\alpha$ expression. (D) Extracellular and intracellular lactate levels in BMDMs incubated overnight (16h) under $21 \%$ or $1.5 \% \mathrm{O}_{2}$. Significance was determined by two-way ANOVA. with Bonferroni's post test. (E) Glycolysis stress test of BMDMs under $1.5 \% \mathrm{O}_{2}$ in combination with echinomycin (16h). (F) Western blot analysis of whole cell extract from BMDMs treated with normoxia $\left(21 \% \mathrm{O}_{2}\right)$ or hypoxia $\left(1.5 \% \mathrm{O}_{2}\right)$ for $16 \mathrm{~h}$. All error bars denote mean $\pm \mathrm{SD}$. ${ }^{*}, \mathrm{p}<0.05$ 
Fiqure 3 bioRxiv preprint doi: https://doi.org/10.1101/2022.02.28.482301; this version posted March 1, 2022. The copyright holder for this preprint 3 (which was not certified by peer review) is the author/funder, who has granted bioRxiv a license to display the preprint in perpetuity. It is made available under aCC-BY-NC-ND 4.0 International license.

A
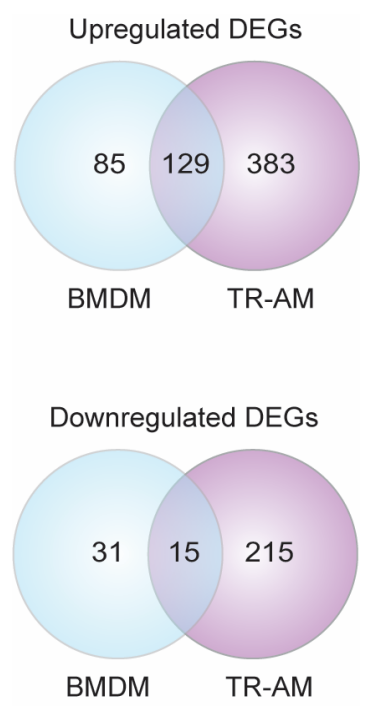

C

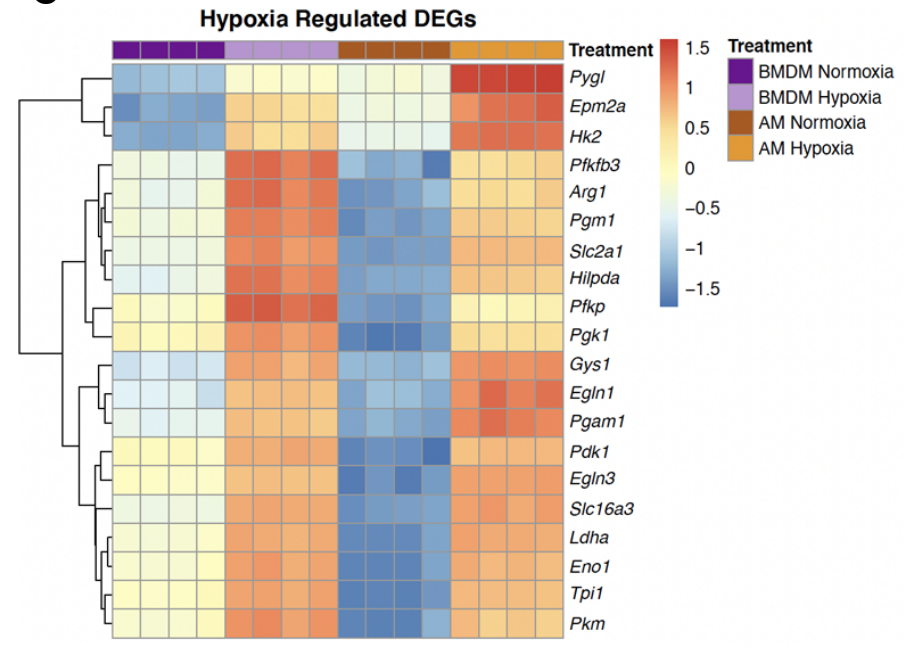

B

Normoxia vs Hypoxia $\left(1.5 \% \mathrm{O}_{2}\right)$

Reactome Pathways $(\mathrm{P}<0.001$ and FDR<0.05)

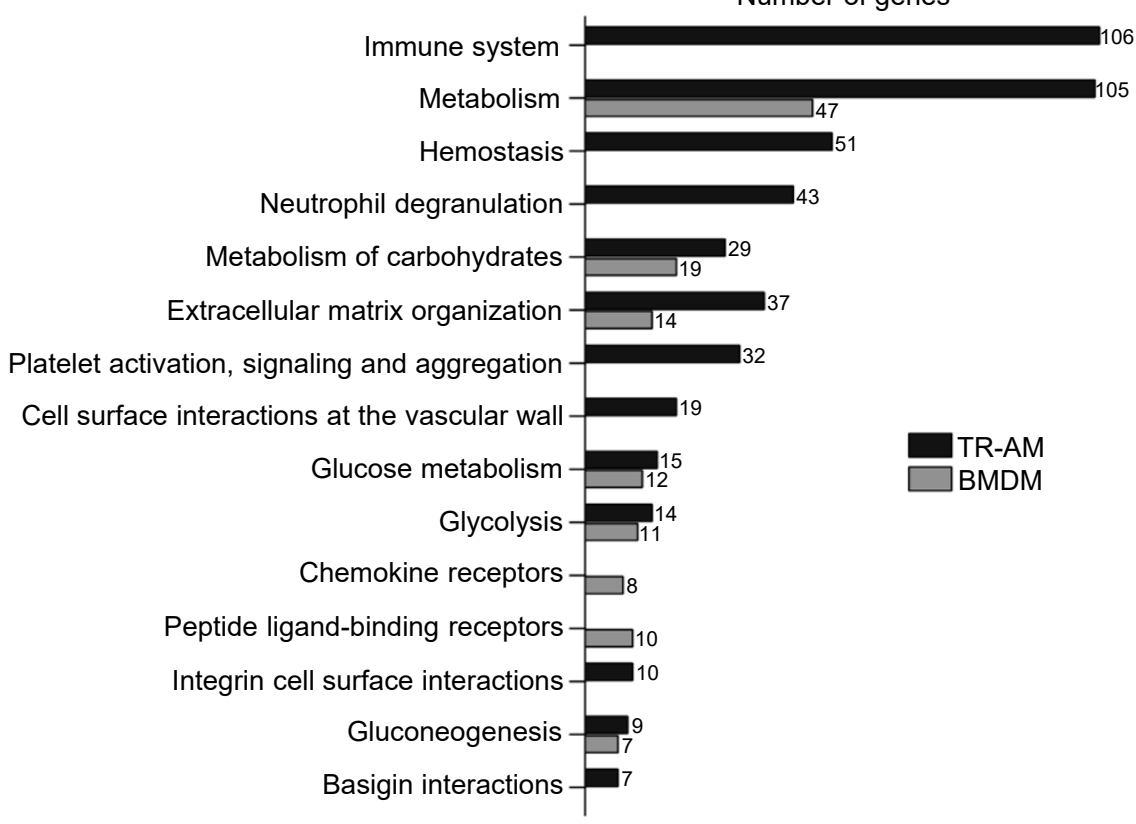

D

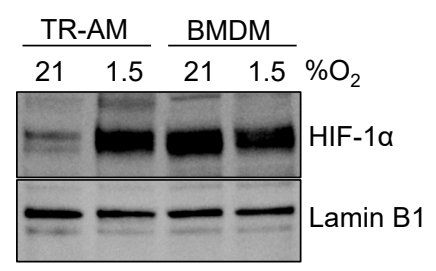

E

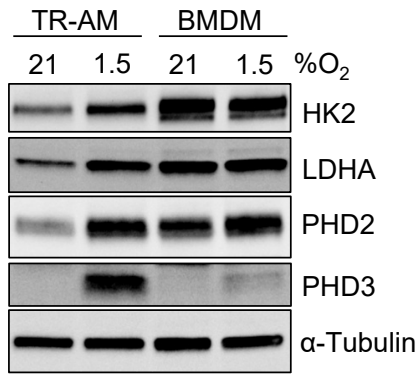

Figure 3. The hypoxia-induced transcriptomic response differs substantially between TR-AMs and BMDMs. TRAMs and BMDMs were incubated overnight $(16 \mathrm{~h})$ under normoxia $\left(21.0 \% \mathrm{O}_{2}\right)$ or hypoxia $\left(\begin{array}{lll}1.5 \% \mathrm{O}_{2}\end{array}\right)$. (A) Venn diagrams show differentially expressed genes (DEGs) altered by hypoxia in TR-AMs (741 total DEGs), and BMDMs (260 total DEGs). DEGs were identified using DESeq2 at FC>2 and FDR adjusted $p$-value of $p<0.05$. (B) Reactome pathway enrichment comparing number of genes in a given pathway altered by hypoxia in TR-AMs and BMDMs. (C) Heatmap representing the top 20 significant metabolic genes altered by hypoxia in both TR-AMs and BMDMs. (D) Western blot analysis of nuclear extracts to assess HIF-1a protein expression. (E) Western blot analysis of whole cell extracts to assess glycolytic enzyme (HK2, LDH) and prolyl hydroxylase (PHD2, PHD3) protein expression. 
Fiqure 4 bioRxiv preprint doi: https://doi.org/10.1101/2022.02.28.482301; this version posted March 1, 2022. The copyright holder for this preprint (which was not certified by peer review) is the author/funder, who has granted bioRxiv a license to display the preprint in perpetuity. It is made available under aCC-BY-NC-ND 4.0 International license.
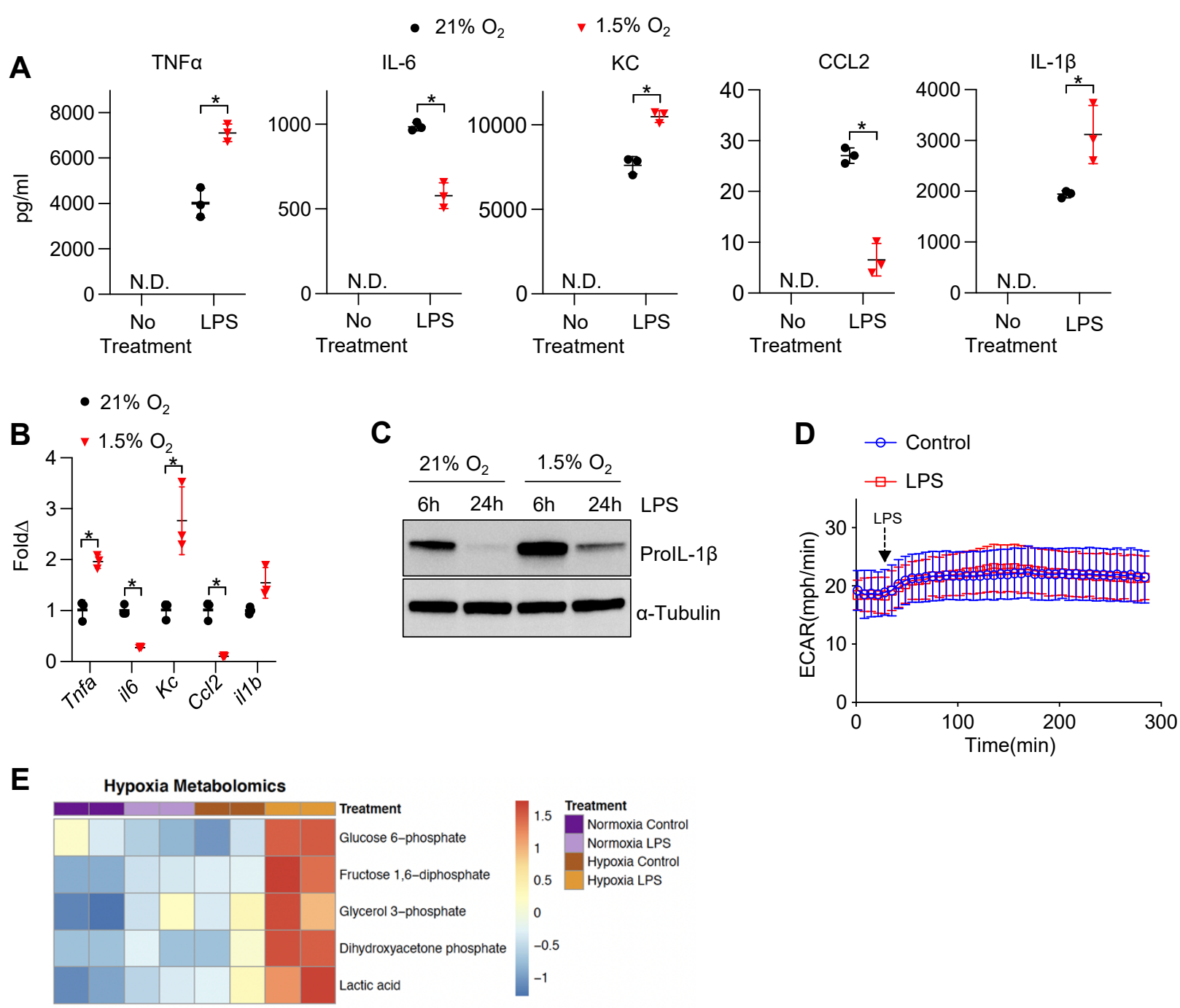

Figure 4. Hypoxia modulates TR-AM cytokine production and metabolic response to LPS. TR-AMs were incubated overnight $(16 \mathrm{~h})$ under $21 \%$ or $1.5 \% \mathrm{O}_{2}$ then stimulated with $20 \mathrm{ng} / \mathrm{ml}$ LPS for 6 while maintaining pretreatment conditions. For IL-1 $\beta$ measurements, $5 \mathrm{mM}$ ATP was added to TR-AMs for 30 minutes following $6 \mathrm{~h}$ LPS treatment to activate caspase 1 , ensuring IL-1 $\beta$ release. (A) We measured cytokine (TNFa, IL-6, KC, CCL2 and IL-1 $\beta$ ) levels in media using ELISA. Data represent at least 3 independent experiments; $n=3$ per group. Significance was determined by two-tailed T Test (B) qPCR was used to measure mRNA expression (Tnfa, il6, Kc, Ccl2, and il1b). Gene expression was normalized to corresponding gene ct values in $21 \%$ group and represented as fold change using the $\Delta \Delta$ ct method. Data represent at least 3 independent experiments; $n=3$ per group. Significance was determined by twotailed T Test (C) Western blot analysis of whole cell extracts at 6 and $24 \mathrm{~h}$ post LPS treatment (D) ECAR was measured in following acute LPS injection (final concentration: $20 \mathrm{ng} / \mathrm{ml}$ ) in TR-AMs conditioned in $1.5 \% \mathrm{O}_{2}$ (E) CE-MS metabolite heatmap for glycolytic intermediates. All error bars denote mean \pm SD. ${ }^{*}, p<0.05$. 
Fiqure 5 bioRxiv preprint doi: https://doi.org/10.1101/2022.02.28.482301; this version posted March 1, 2022. The copyright holder for this preprint (which was not certified by peer review) is the author/funder, who has granted bioRxiv a license to display the preprint in perpetuity. It is made available under aCC-BY-NC-ND 4.0 International license.
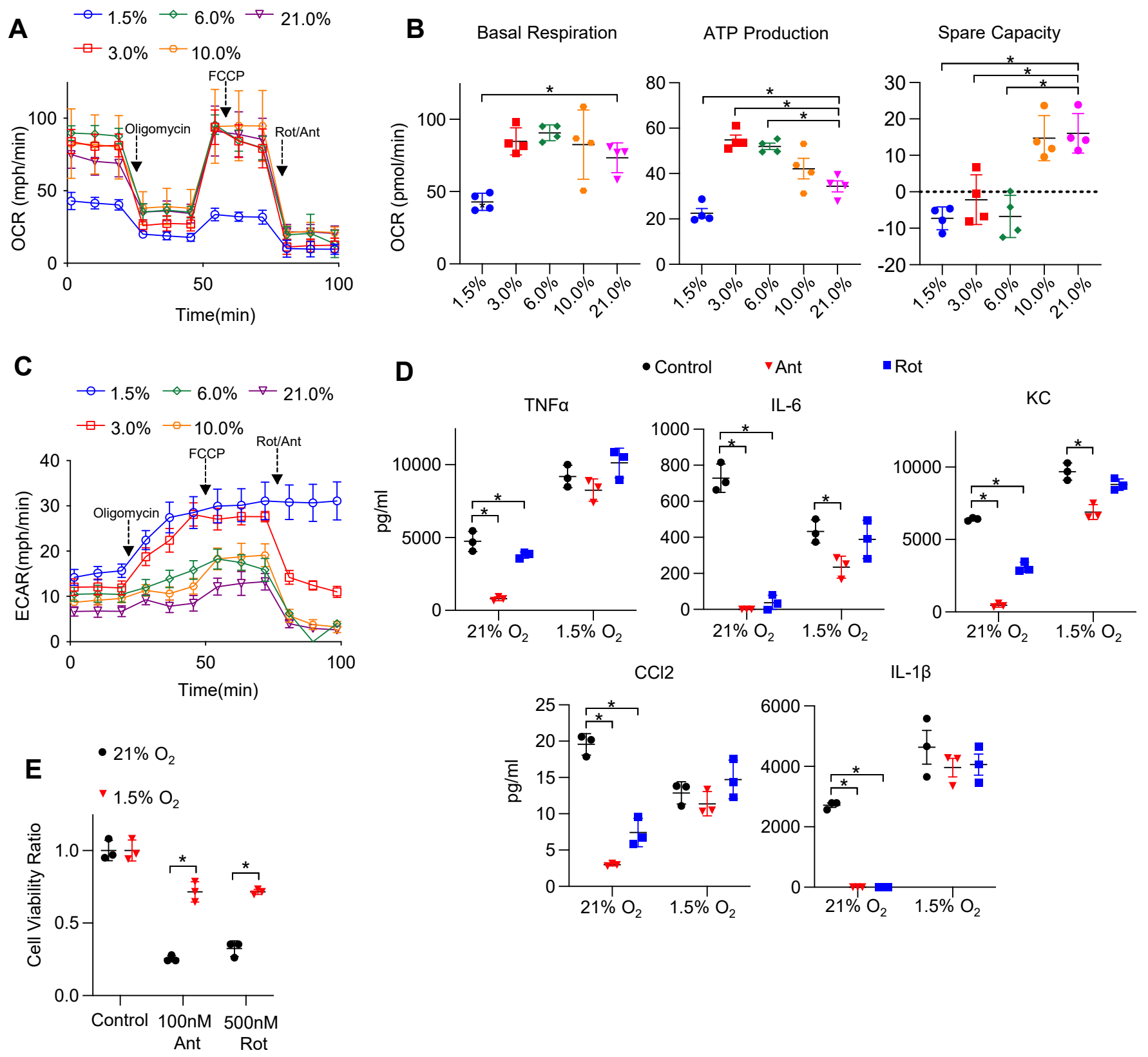

Figure 5. Hypoxia rescues ETC inhibitor-induced cell death and impaired cytokine production in TR-AMs. (A) Mitochondrial stress test to measure oxygen consumption rate (OCR) using Seahorse XF24 in TR-AMs, which were treated sequentially with oligomycin (ATP synthase inhibitor), FCCP (uncoupler) and Rotenone (Rot)/Antimycin A (Ant) (complex I and III inhibitors, respectively). (B) Interleaved scatter plots quantifying mitochondrial respiration parameters. Data represents at least 3 experiments $(n=4$ separate wells per group). Mitochondrial parameters were were compared against $21 \% \mathrm{O}_{2}$ and significance was determined by one-way ANOVA with Bonferroni's post test (C) ECAR measurement during mitochondrial stress test to visualize TR-AMs ability to upregulate glycolysis in response to mitochondrial inhibition (D) TR-AMs were incubated overnight (16h) under $21 \%$ or $1.5 \% \mathrm{O}_{2}$ then stimulated with $20 \mathrm{ng} / \mathrm{ml}$ LPS in the presence of absence of mitochondrial inhibitors (20nM Ant or Rot) for 6 hours while maintaining pretreatment conditions. ELISA was used to measure secreted cytokine (TNFa, IL-6, KC, CCL2, and IL-1 $\beta$ ) levels in media. ATP added to cells prior to collection for IL-1 $\beta$ assessment. Data represent at least 3 independent experiments; $\mathrm{n}=3$ per group. Significance was determined by one-way ANOVA with Bonferroni's post test. (E) TR-AMs were cultured under $21 \%$ or $1.5 \% \mathrm{O}_{2}$ for $6 \mathrm{~h}$ then treated with mitochondrial inhibitors (100nM Ant or 500nM Rot) overnight and an Sulforhodamine B assay was performed to measure cytotoxicity. Graphs represent cell viability compared to control, $21 \% \mathrm{O}_{2}$ group. Data represent at least 3 independent experiments ( $n=3$ per group). Significance was determined by two-way ANOVA with Bonferroni's post test. All error bars denote mean \pm SD. * $p<0.05$. 
Fiqure 6 bioRxiv preprint doi: https://doi.org/10.1101/2022.02.28.482301; this version posted March 1, 2022. The copyright holder for this preprint (which was not certified by peer review) is the author/funder, who has granted bioRxiv a license to display the preprint in perpetuity. It is made available under aCC-BY-NC-ND 4.0 International license.

A

TR-AMs (PKH26+)

Mo-AMs (PKH26-)

D0
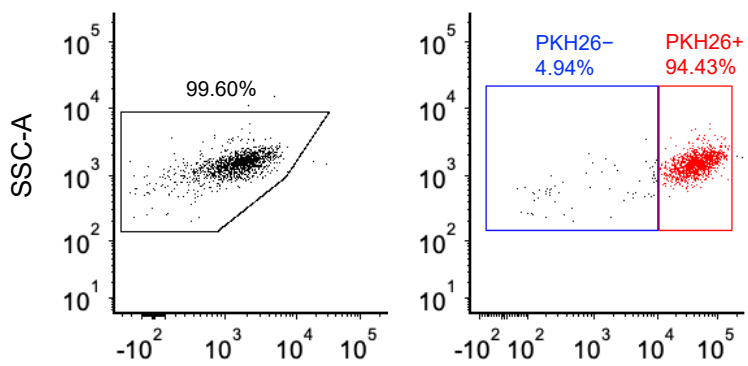

D3
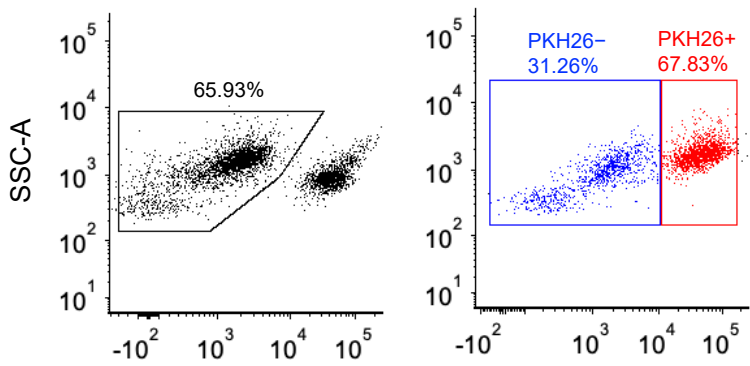

D6

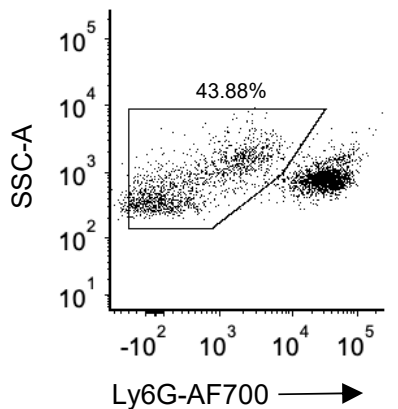

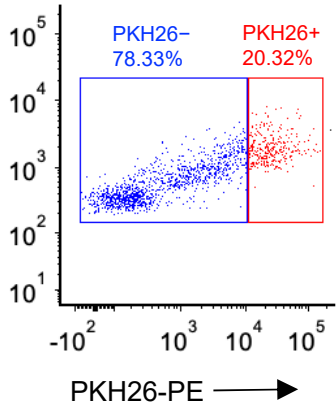

B

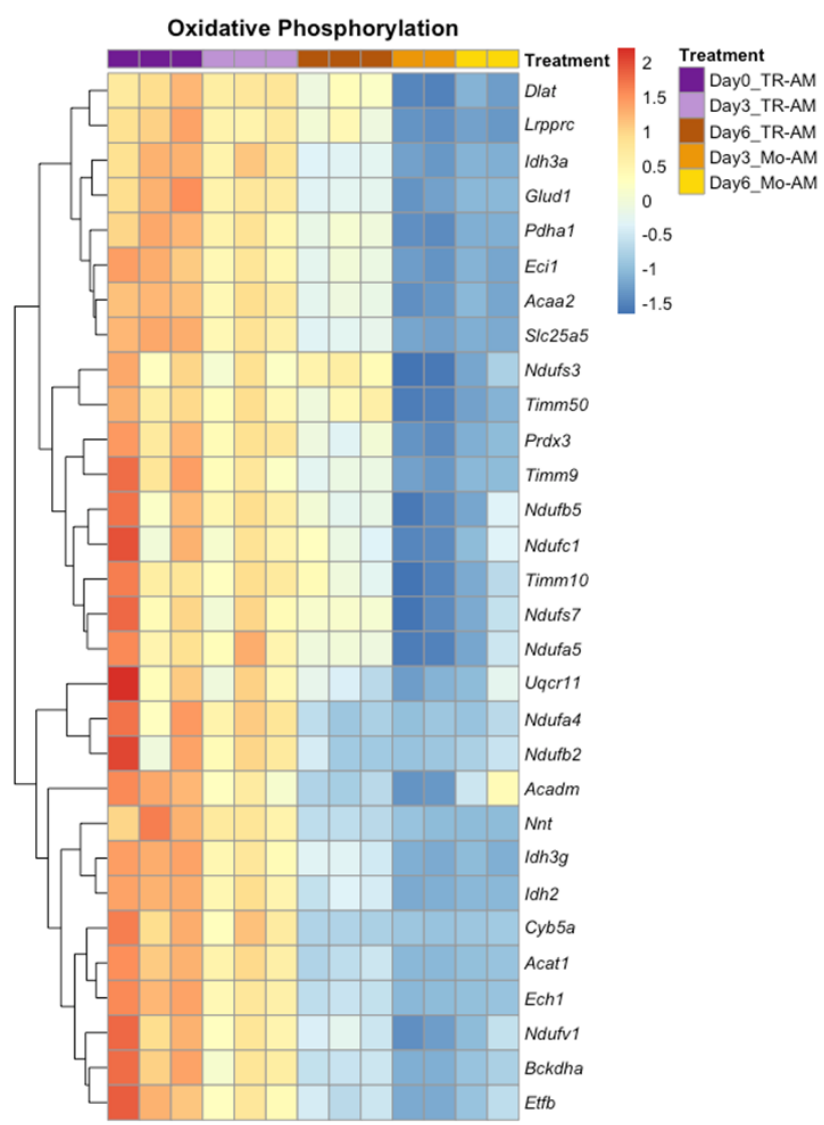

C

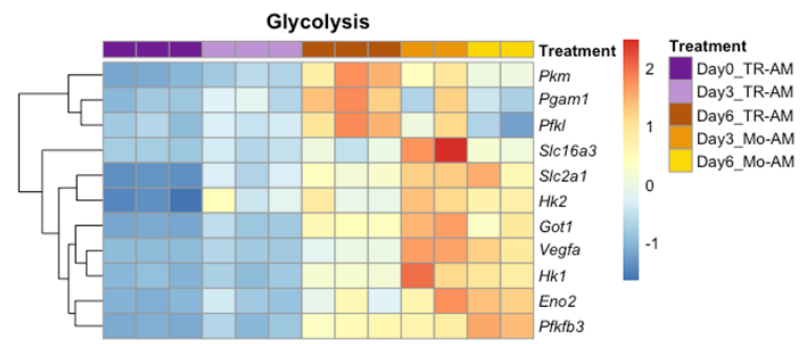

Figure 6. TR-AM survival correlates with a shift to glycolytic metabolism during influenza-induced acute lung injury (A) FACS plots of BALF samples collected from C57BL/6 mice infected with PR8 (100 PFU) at baseline (D0), 3 days (D3) and 6 days (D6) post infection. First, debris, red blood cells, and lymphocytes were eliminated based on size (FSC) and granularity (SSC). Samples were first gated on single cells based on the side scatter (SSC)/forward scatter signal (FSC), and then live cells were selected (SYTOX Green-). Ly6G- used to exclude neutrophils. TR-AMs were identified as being $\mathrm{PKH} 26+$, and nonresident/infiltrating Mo-AMs were $\mathrm{PKH} 26-$. Gene expression heatmaps representing (B) oxidative phosphorylation and (C) glycolytic gene expression. Heatmaps were generated through DEG analysis of UniProt oxidative phosphorylation and glycolysis gene sets for FAC TR-AMs ( $\mathrm{PKH}+; \mathrm{n}=3 / \mathrm{group})$ and MoAMs (PKH26- ; n=2/group) over the infection time course. 
Fiqure 7 bioRxiv preprint doi: https://doi.org/10:1101/2022.02.28.482301; this version posted March 1, 2022. The copyright holder for this preprint (which was not certified by peer review) is the author/funder, who has granted bioRxiv a license to display the preprint in perpetuity. It is made available under aCC-BY-NC-ND 4.0 International license.

A $\quad-0.0 \mu \mathrm{M} \triangle 25 \mu \mathrm{M}$
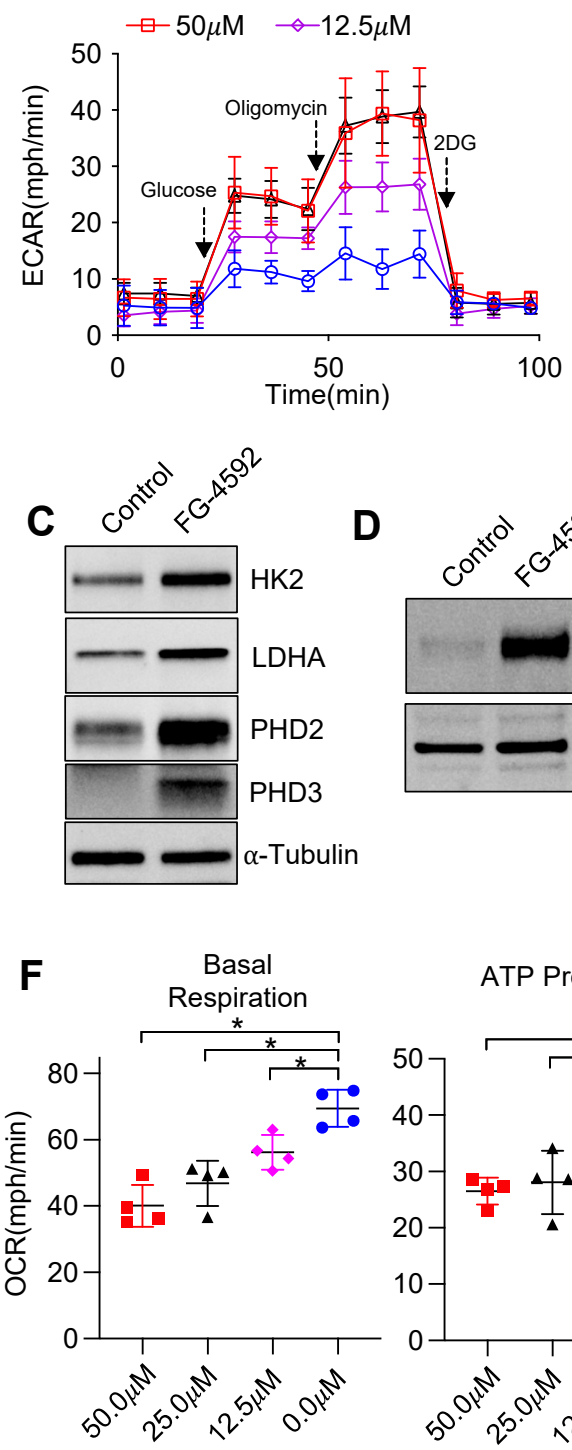

H
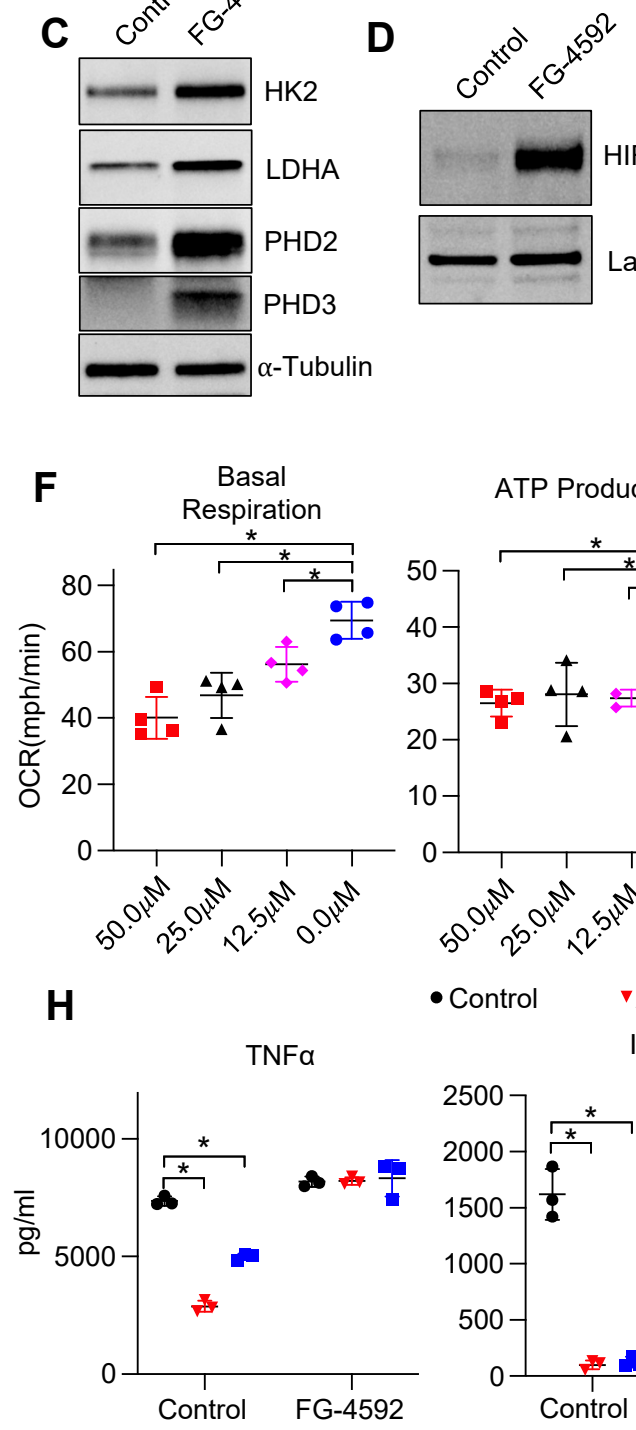
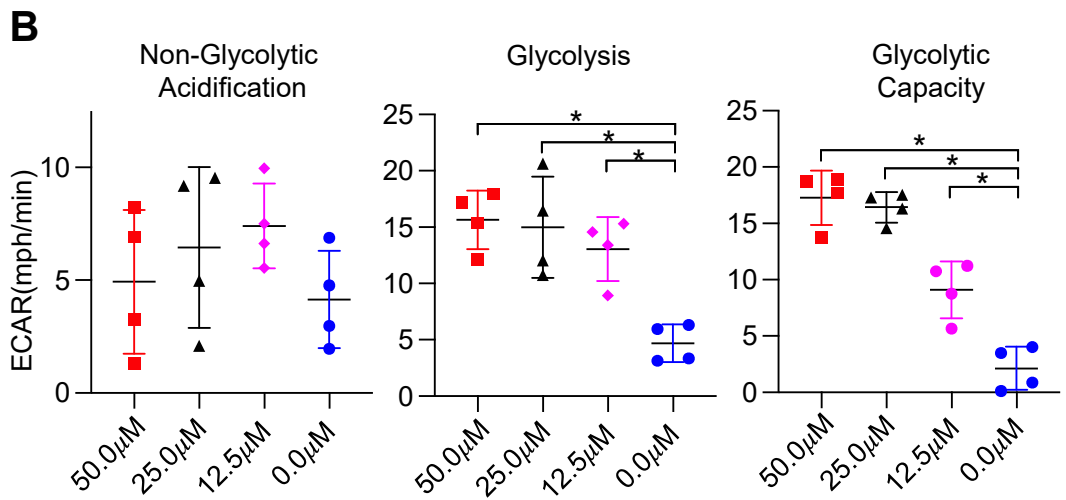

E $-0.0 \mu \mathrm{M} \triangle 25.0 \mu \mathrm{M}$

$$
\neg 50.0 \mu \mathrm{M} \rightarrow-12.5 \mu \mathrm{M}
$$
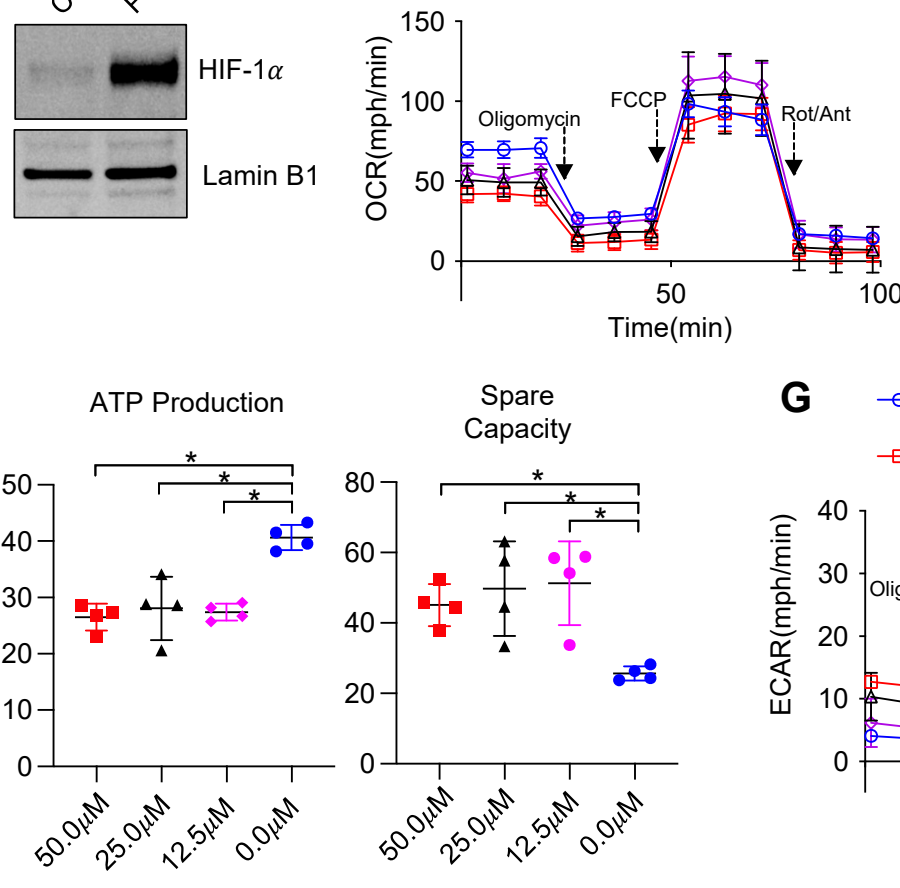

G $\begin{array}{r}-0.0 \mu \mathrm{M} \rightarrow 25.0 \mu \mathrm{M} \\ -50.0 \mu \mathrm{M} \multimap-12.5 \mu \mathrm{M}\end{array}$
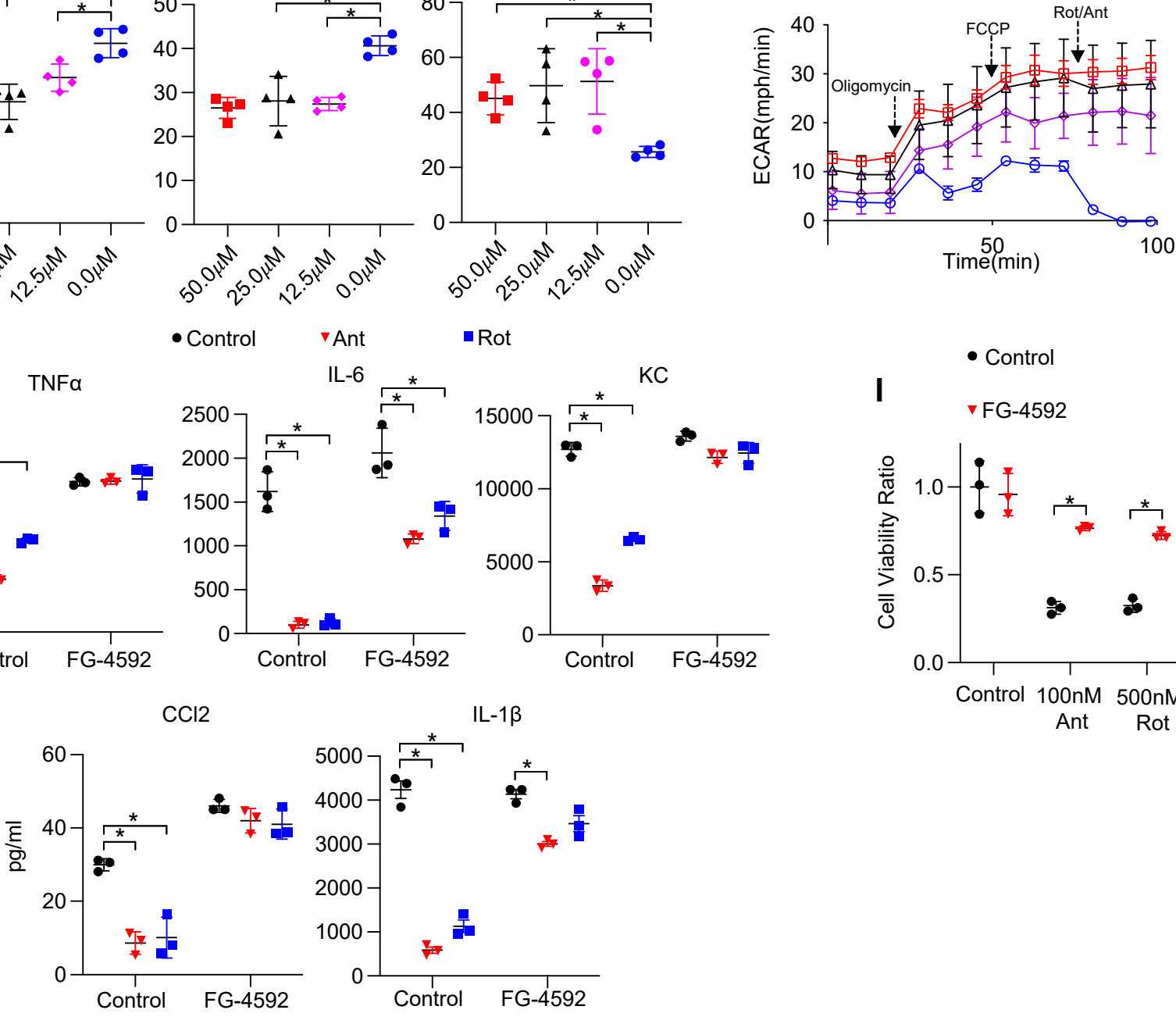
Figure 7. Non-hypoxic stabilization of HIF-1a increases TR-AM survival and improves outcomes in influenzainduced acute lung injury. TR-AMs were treated (16h) overnight \pm FG-4592 (25.0 $\mu \mathrm{M}$ when not stated otherwise). (A) Glycolysis was measured as extracellular acidification rate (ECAR). (B) Quantification of glycolytic parameters. Data represent at least 3 independent experiments ( $n=4$ separate wells per group). Glycolytic parameters compared to control group $(0.0 \mu \mathrm{M})$ and significance was determined by one-way ANOVA with Bonferroni's post test (C) Western blot analysis of whole cell lysate. (D) nuclear extract. (E) Mitochondrial stress test to measure oxygen consumption rate (OCR). (F) Quantification of mitochondrial respiration parameters. Data represents at least 3 experiments $(n=4$ separate wells per group). Mitochondrial parameters were compared to control group $(0.0 \mu \mathrm{M})$ and significance was determined by one-way ANOVA with Bonferroni's post test (G) ECAR measurement during mitochondrial stress test. (H) TR-AMs were pretreated overnight (16h) with $0.0 \mu \mathrm{M}$ (no treatment) or $25.0 \mu \mathrm{M}$ FG-4592 then stimulated with $20 \mathrm{ng} / \mathrm{ml}$ LPS in the presence of absence of mitochondrial inhibitors (20nM Antimycin A (Ant) or Rotenone (Rot)) for 6 hours while maintaining pretreatment conditions. Sandwich ELISA was used to measure secreted cytokine (TNFa, IL-6, $\mathrm{KC}$ and CCL-2). Data represents at least 3 independent experiments; $n=3$ per group. (I) TR-AMs were treated with FG4592 for $6 \mathrm{~h}$ then treated with mitochondrial inhibitors (100nM Ant or 500nM Rot) overnight and an SRB assay was performed to measure cytotoxicity. Bar graphs represent cytotoxicity compared to control, 0.0uM group. Data represents at least 3 independent experiments ( $n=3$ per group). Significance was determined by two-way ANOVA with Bonferroni's post test. All error bars denote mean \pm SD. *,$p<0.05$ 
Fiqure 8 bioRxiv preprint doi: https://doi.org/10.1101/2022.02.28.482301; this version posted March 1, 2022. The copyright holder for this preprint (which was not certified by peer review) is the author/funder, who has granted bioRxiv a license to display the preprint in perpetuity. It is made available under aCC-BY-NC-ND 4.0 International license.

A

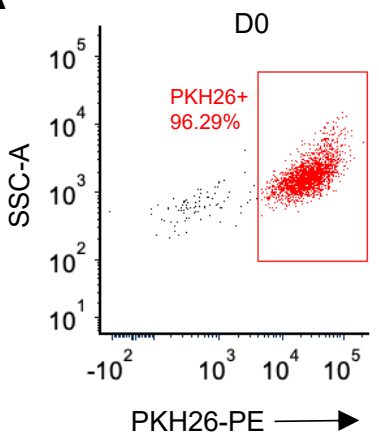

B

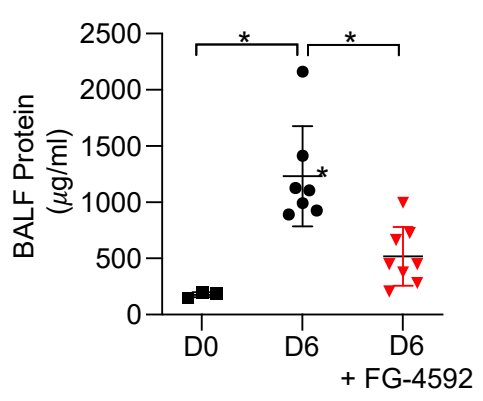

D6

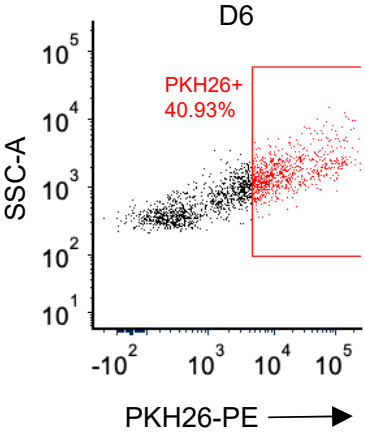

D6 + FG-4592

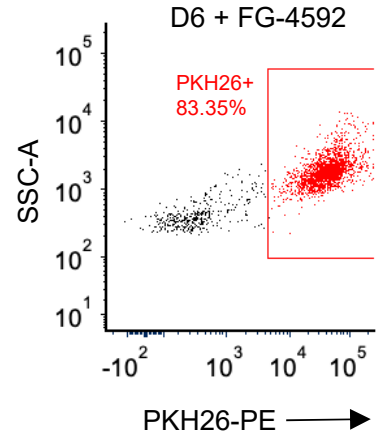

D

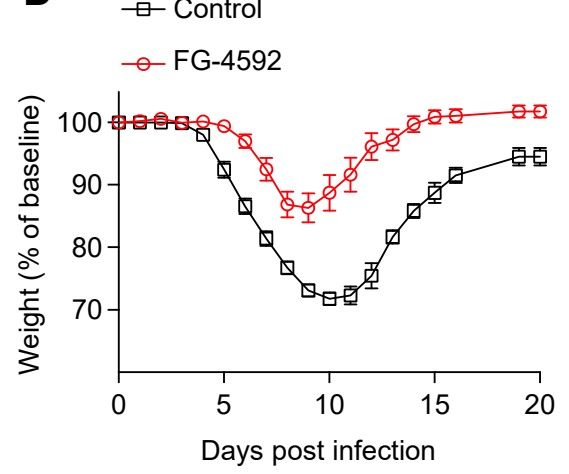

C

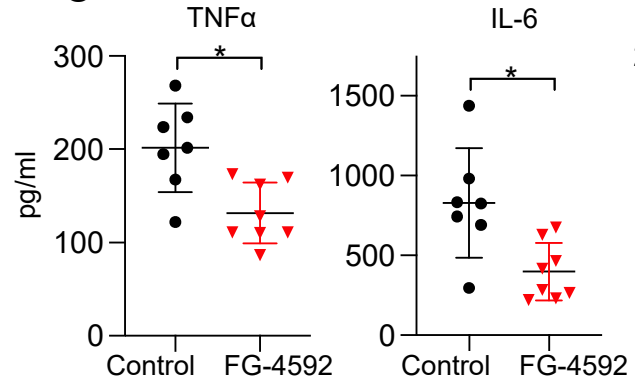

$\mathrm{IL}-1 \beta$

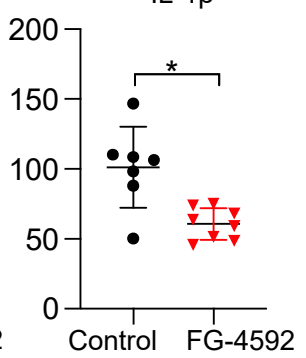

Figure 8. Non-hypoxic stabilization of HIF-1 $\alpha$ increases TR-AM survival and improves outcomes in influenzainduced acute lung injury. We intratracheally infected C57BL/6 mice with PR8 (100 pfu) and collected bronchoalveolar lavage fluid (BALF) on day 0 (D0) (uninfected) and day 6 (D6) post-infection. Mice also received either the HIF-1 $\alpha$ stabilizer (FG-4592) or vehicle control on D0. (A) Representative FACS plot of BALF macrophages. (B) BALF protein concentration (C) BALF proinflammatory cytokine levels at D6. BALF data generated from 2 separate experiments ( $n=7$ mice/control group and $n=8$ mice/FG-4592 group) BALF data significance was determined by twotailed Student's t test. (D,E) C57BL/6 mice infected with PR8 (200pfu) (10 mice/group). (D) Weight loss represented as percentage and normalized to D0. (E) Survival curve. ${ }^{*} p<0.05$. All error bars denote mean \pm SD. 
Fiqure S1 bioRxiv preprint doi: https://doi.org/10.1101/2022.02.28.482301; this version posted March 1, 2022. The copyright holder for this preprint which was not certified by peer review) is the author/funder, who has granted bioRxiv a license to display the preprint in perpetuity. It is made available under aCC-BY-NC-ND 4.0 International license.

A
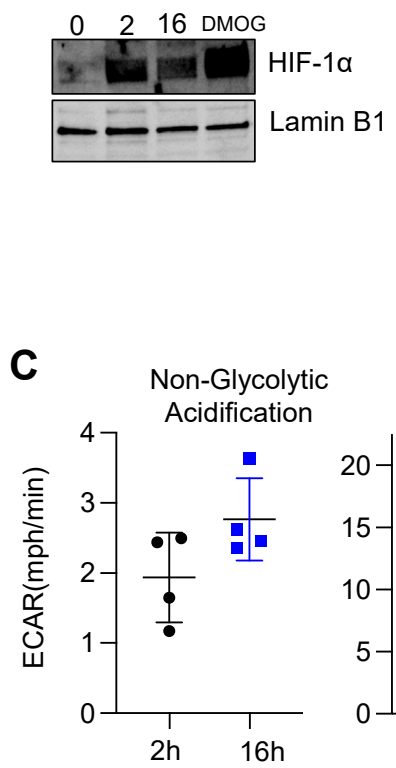

B
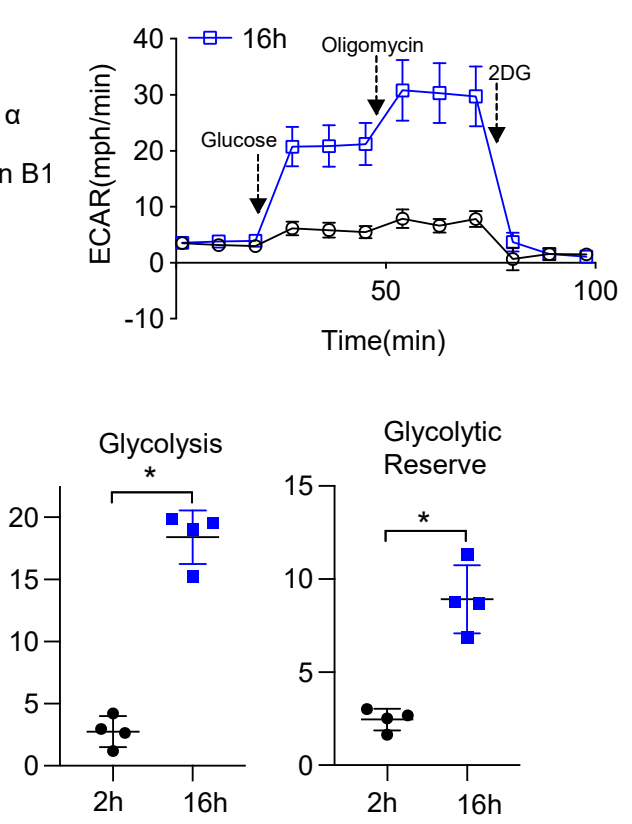

Glycolytic

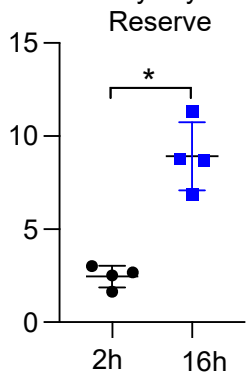

Figure S1. Prolonged but not short-term hypoxia induces glycolysis in TR-AMs. TR-AMs were incubated for $2 \mathrm{~h}$ or overnight (16h) at $1.5 \% \mathrm{O}_{2}$. (A) Western blot analysis of nuclear extracts to assess HIF-1a protein expression. (B) Using Seahorse XF24 technology, glycolysis was measured as extracellular acidification rate (ECAR). (C) Interleaved scatter plots quantifying glycolytic parameters. Data represents at least 3 independent experiments $(n=4$ separate wells per group). Significance was determined by two-tailed Student's t test. * $p<0.05$. 
Figure S2 bioRxiv preprint doi: https://doi.org/10.1101/2022.02.28.482301; this version posted March 1, 2022. The copyright holder for this preprint the author/funder, who has granted bioRxiv a license to display the preprint in perpetuity. It is made available under aCC-BY-NC-ND 4.0 International license.

A
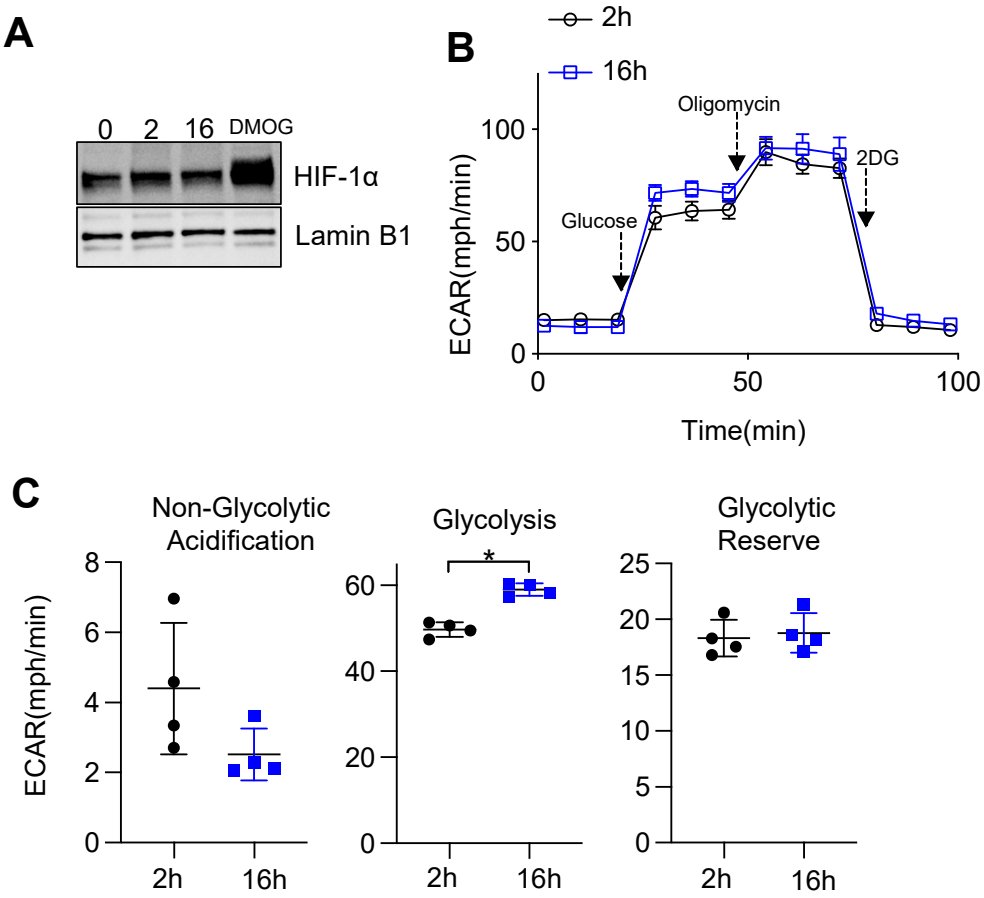

Figure S2. Short-term or prolonged hypoxia has no significant effect on HIF-1a expression or glycolysis in BMDMs. BMDMs were incubated for $2 \mathrm{~h}$ or overnight $(16 \mathrm{~h})$ at $1.5 \% \mathrm{O}_{2}$. (A) Western blot analysis of nuclear extracts to assess HIF-1a protein expression. (B) Using Seahorse XF24 technology, glycolysis was measured as extracellular acidification rate (ECAR). (C) Interleaved scatter plots quantifying glycolytic parameters. Data represents at least 3 independent experiments ( $n=4$ separate wells per group). Significance was determined by two-tailed Student's $t$ test. ${ }^{*}, p<0.05$ 
Fiaure S3bioRxiv preprint doi: https://doi.org/10.1101/2022.02.28.482301; this version posted March 1, 2022. The copyright holder for this preprint which was not certified by peer review) is the author/funder, who has granted bioRxiv a license to display the preprint in perpetuity. It is made available under aCC-BY-NC-ND 4.0 International license.

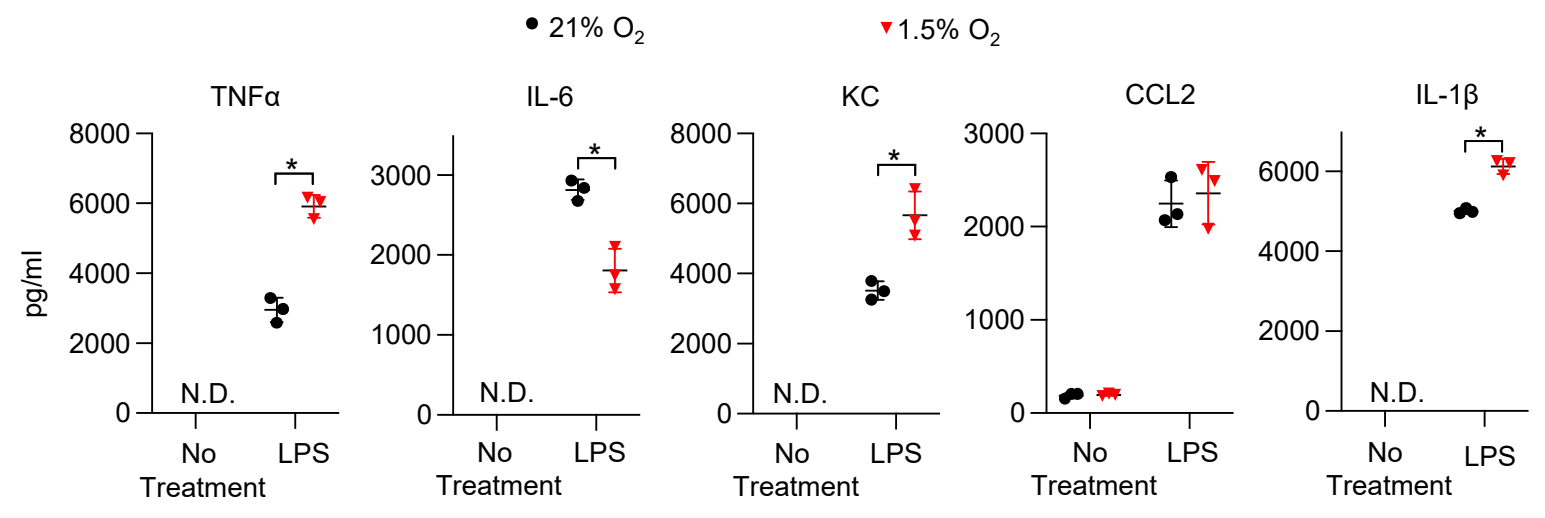

Figure S3 Hypoxia alters cytokine production in BMDMs. BMDMs were incubated overnight (16h) under normoxia or $1.5 \% \mathrm{O}_{2}$ then stimulated with $20 \mathrm{ng} / \mathrm{ml}$ LPS for 6 hours while maintaining pretreatment conditions. For IL- $1 \beta, 5 \mathrm{mM}$ ATP was added to BMDMs for 30 minutes following $6 \mathrm{~h}$ LPS treatment to activate caspase 1, ensuring IL-1 $\beta$ release. (A) Sandwich ELISA was used to measure secreted cytokine (TNFa, IL-6, KC, CCL2 and IL-1 $\beta$ ). Data represents at least 3 independent experiments; $n=3$ per group. Significance was determined by two-tailed T Test. All error bars denote mean $\pm S D .{ }^{*}, p<0.05$ 
Figure S4bioRxiv preprint doi: https://doi.org/10.1101/2022.02.28.482301; this version posted March 1, 2022. The copyright holder for this preprint which was not certified by peer review) is the author/funder, who has granted bioRxiv a license to display the preprint in perpetuity. It is made available under aCC-BY-NC-ND 4.0 International license.

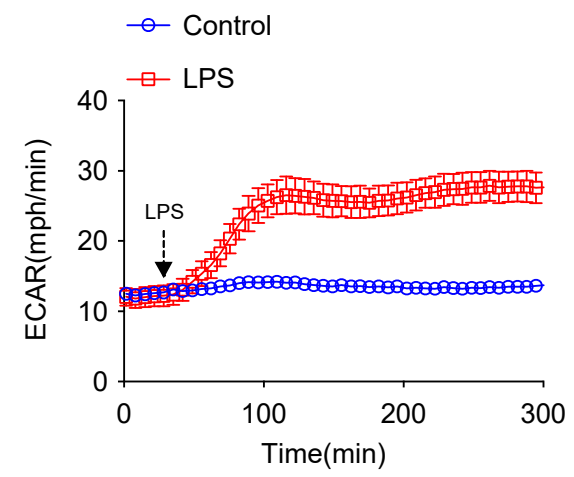

Figure S4 LPS induces an immediate increase in glycolysis in BMDMs. ECAR was measured in normoxic BMDMs following acute LPS injection (final concentration: $20 \mathrm{ng} / \mathrm{ml}$ ). 
Fiqure S5 bioRxiv preprint doi: https://doi.org/10.1101/2022.02.28.482301; this version posted March 1, 2022. The copyright holder for this preprint (Which was not certified by peer review) is the author/funder, who has granted bioRxiv a license to display the preprint in perpetuity. It is made available under aCC-BY-NC-ND 4.0 International license.

A

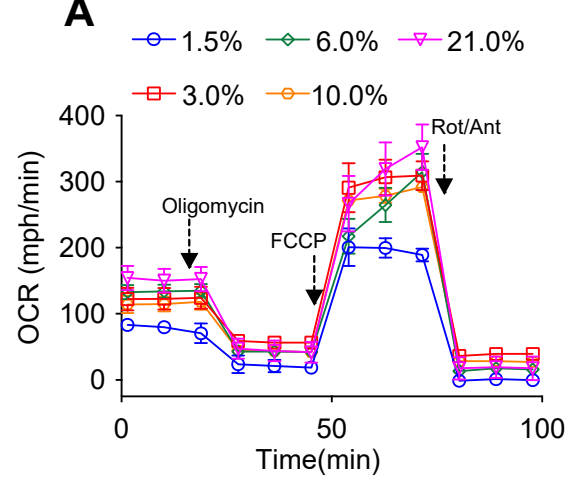

C

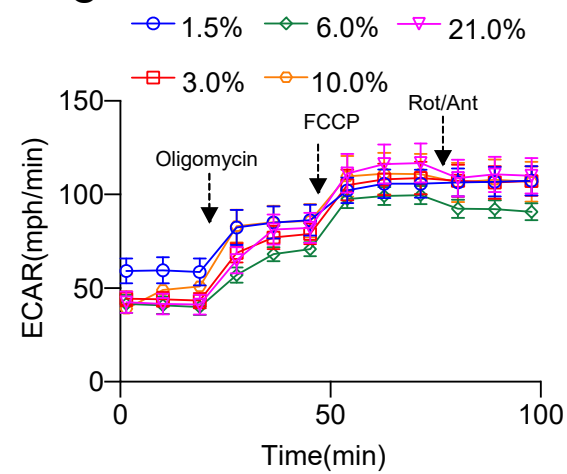

E $\begin{aligned} & \cdot 21 \% \mathrm{O}_{2} \\ & \quad \nabla 1.5 \% \mathrm{O}_{2}\end{aligned}$

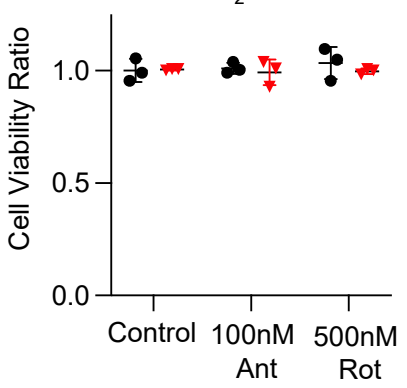

B Basal Respiration

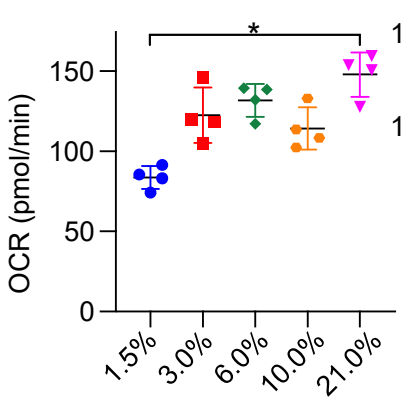

D

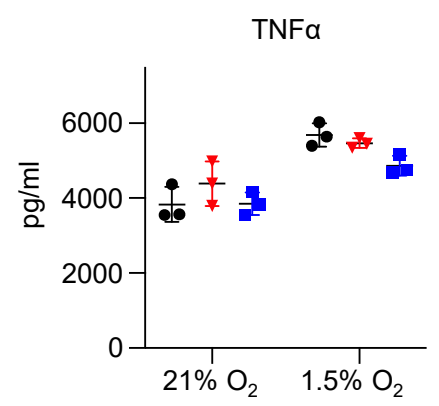

ATP Production

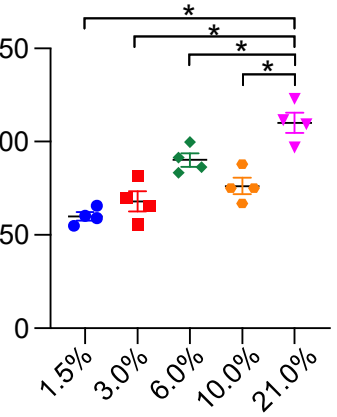

- Control

$\checkmark$ Ant
IL-6

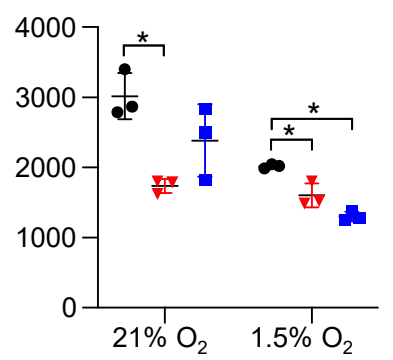

$\mathrm{CCl} 2$
Spare Capacity

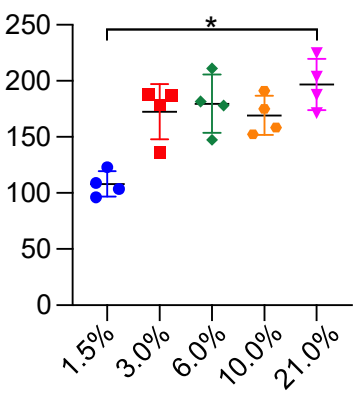

- Rot

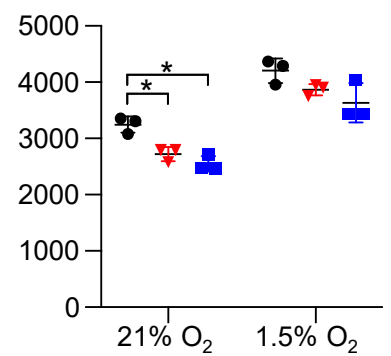

IL-1ß

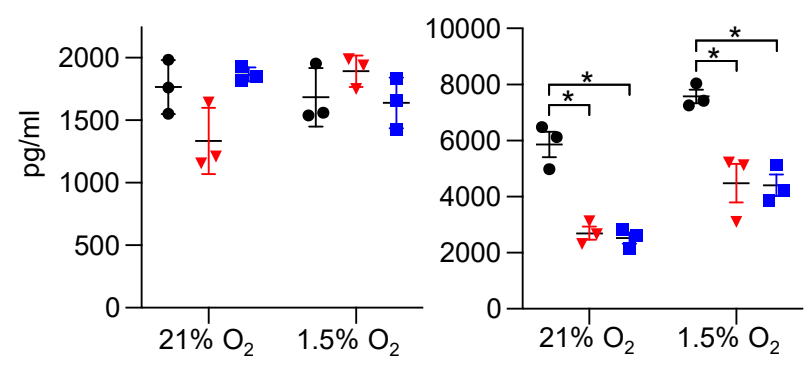

Figure S5. The effect of hypoxia on BMDM mitochondrial function, cytokine production and cell liability under ETC inhibition. (A) Mitochondrial stress test to measure oxygen consumption rate (OCR) using Seahorse XF24 in BMDMs. (B) Interleaved scatter plots quantifying mitochondrial respiration parameters. Data represents at least 3 experiments ( $n=4$ separate wells per group). Mitochondrial parameters were were compared against $21 \% \mathrm{O}_{2}$ and significance was determined by one-way ANOVA with Bonferroni's post test (C) ECAR measurement during mitochondrial stress test. (D) BMDMs were incubated overnight (16h) under $21 \%$ or $1.5 \% \mathrm{O}_{2}$ then stimulated with $20 \mathrm{ng} / \mathrm{ml}$ LPS in the presence of absence of mitochondrial inhibitors (20nM Antimycin A (Ant) or Rotenone (Rot)) for 6 hours while maintaining pretreatment conditions. ELISA was used to measure secreted cytokine (TNFa, IL-6, KC, CCL2, and IL-1 $\beta$ ) levels in media. ATP added to cells prior to collection for IL-1 $\beta$ assessment. Data represent at least 3 independent experiments; $n=3$ per group. Significance was determined by one-way ANOVA with Bonferroni's post test. (E) BMDMs were cultured under $21 \%$ or $1.5 \% \mathrm{O}_{2}$ for $6 \mathrm{~h}$ then treated with mitochondrial inhibitors (100nM Ant or 500nM Rot) overnight and an Sulforhodamine B assay was performed to measure cytotoxicity. Graphs represent cell viability compared to control, $21 \% \mathrm{O}_{2}$ group. Data represent at least 3 independent experiments ( $\mathrm{n}=3$ per group). Significance was determined by two-way ANOVA with Bonferroni's post test. All error bars denote mean $\pm \mathrm{SD}$. ${ }^{*}, \mathrm{p}<0.05$. 